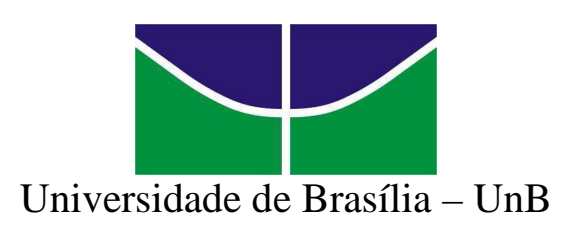

FACULDADE DE ECONOMIA, ADMINISTRAÇÃO, CONTABILIDADE E CIÊNCIA DA INFORMAÇÃO E DOCUMENTAÇÃO - FACE

ELIENE VILAS BOAS LEMOS

\title{
ALINHAMENTO ESTRATÉGICO NA VISÃO DE GERENTES DA SECRETARIA DE RECURSOS HUMANOS DA UnB
}




\title{
ALINHAMENTO ESTRATÉGICO NA VISÃO DE GERENTES DA SECRETARIA DE RECURSOS HUMANOS DA UnB
}

\begin{abstract}
Monografia apresentada no curso de Gestão Universitária do Programa de Pós-Graduação em Administração da Faculdade de Economia, Administração, Contabilidade e Ciência da Informação e Documentação - FACE, da Universidade de Brasília, como requisito parcial para obtenção do grau de Especialista em Gestão Universitária.
\end{abstract}

Orientadora: Profa. MSc. Josivania Silva Farias. 


\section{FICHA CATALOGRÁFICA}

LEMOS, ELIENE VILAS BOAS

Alinhamento estratégico na visão de Gerentes da Secretaria de Recursos Humanos da UnB [Distrito Federal]2009.

56 p., (FACE/ UnB, Especialista, Gestão Universitária, 2009).

Monografia ao grau de Especialista - Universidade de Brasília. Faculdade de Economia, Administração, Contabilidade e Ciência da Informação e Documentação.

\section{REFERÊNCIA BIBLIOGRÁFICA}

LEMOS, ELIENE VILAS BOAS; Alinhamento estratégico na visão de Gerentes da Secretaria de Recursos Humanos da UnB. Monografia de Especialização, Faculdade de Economia, Administração, Contabilidade e Ciência da Informação e Documentação, DF, $56 \mathrm{p}$.

\section{CESSÃO DE DIREITOS}

NOME DO AUTOR: ELIENE VILAS BOAS LEMOS

TÍTULO DA MONOGRAFIA: ALINHAMENTO ESTRATÉGICO NA VISÃO DE GERENTES DA SECRETARIA DE RECURSOS HUMANOS DA UnB.

GRAU/ ANO: ESPECIALISTA/ 2009.

É concedida à Universidade de Brasília permissão para reproduzir cópias desta monografia ao grau de especialista e para emprestar ou vender tais cópias somente para propósito acadêmico e científico. $\mathrm{O}$ autor reserva outros direitos de publicação e nenhuma parte desta monografia de especialização pode ser reproduzida sem autorização por escrito do autor.

ELIENE VILAS BOAS LEMOS 


\section{AGRADECIMENTOS}

A Deus, pelo dom da vida e fonte de sabedoria.

Aos meus pais, razão de esforço e motivo de orgulho.

À minha orientadora, Profa. Josivania Farias, pelo incentivo e paciência em cada passo desta conquista.

Aos meus colegas de sala, pela amizade e persistência nesta luta e a todos aqueles que de forma direta ou indireta, contribuíram para que eu pudesse concluir este trabalho. 


\section{RESUMO}

Este estudo buscou mostrar o alinhamento entre o planejamento estratégico da Universidade de Brasília e as atividades de planejamento desenvolvidas nas gerências da Secretaria de Recursos Humanos - SRH. Para tanto, foi conduzida uma pesquisa descritiva, através de análise documental e de estudo de caso. Os dados coletados nas entrevistas com os gerentes da SRH foram interpretados por meio de mecanismos de análise propostos por Bardin (2004 apud SENNA, 2007) ao tratar da técnica de Análise de Conteúdo. Os resultados obtidos apontam para uma falta de integração das gerências, bem como o insuficiente conhecimento do planejamento estratégico da UnB.

Palavras-chave: planejamento estratégico; gestão estratégica; alinhamento. 


\section{LISTA DE FIGURAS}

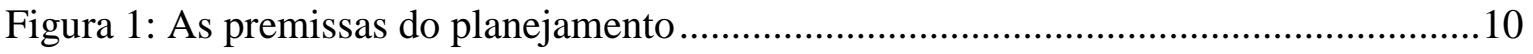

Figura 2: Níveis de decisão e tipos de planejamento.........................................................11

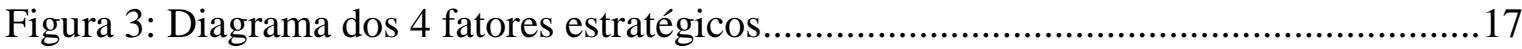

Figura 4: Modelo de Administração Estratégica .................................................................20

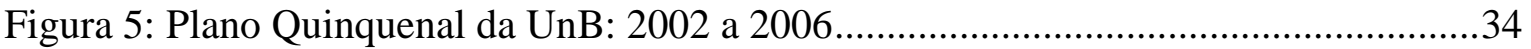

Figura 6: Ciclo Quinquenal de Acompanhamento e Avaliação do Sistema de

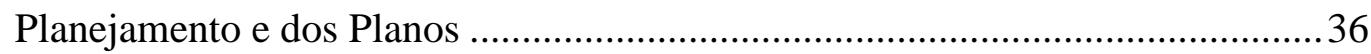




\section{LISTA DE QUADROS}

Quadro 1: Quadro dos tipos e níveis do Planejamento Estratégico.....................................12

Quadro 2: Categoria Conhecimento das metas da SRH do PDI da UnB ..........................40

Quadro 3: Categoria Percepção quanto a parceria da SRH com a UnB no Planejamento

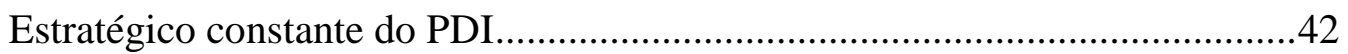

Quadro 4: Categoria Participação e importância da SRH no Planejamento Estratégico da $\mathrm{UnB}$

Quadro 5: Categoria Relação entre as atividades executadas na área de RH e o PDI da $\mathrm{UnB}$ .46

Quadro 6: Categoria Relação de equipe de trabalho e o planejamento estratégico da $\mathrm{UnB}$ 47

Quadro 7: Categoria Participação da Gerência no planejamento da UnB 


\section{SUMÁRIO}

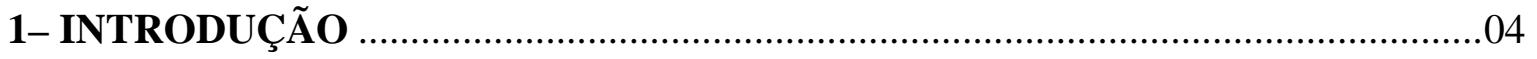

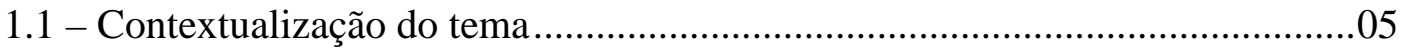

1.2 - O problema de pesquisa ...................................................................................

1.3 - Definição da pergunta da pesquisa …………………………………………....07

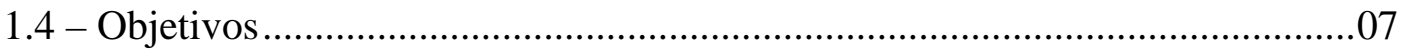

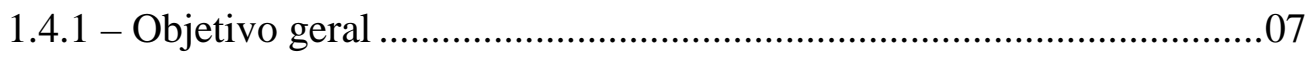

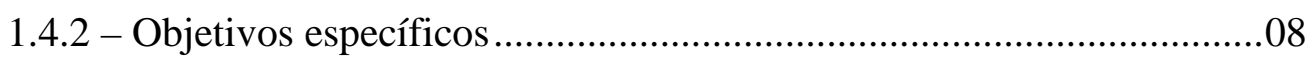

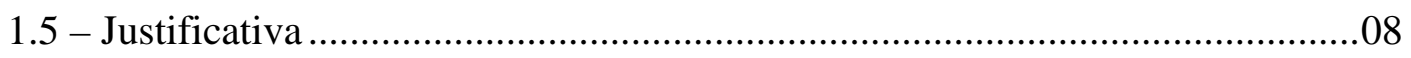

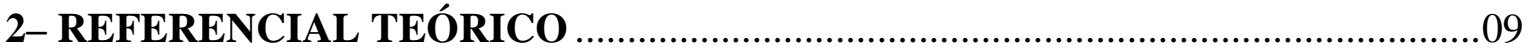

2.1 - Conceituação de planejamento ………………………………………….......

2.1.1 - Tipos de planejamento....................................................................12

2.2 - Planejamento Estratégico ……………………………………………....12

2.3 - Gestão Estratégica Organizacional ...............................................................15

2.4 - Estratégia na área de Recursos Humanos ........................................................20

2.5 - Estudos semelhantes desenvolvidos no tema .................................................21

3 -METODOLOGIA

3.1 - Tipo de Pesquisa ..........................................................................................24

3.2 - Os sujeitos da pesquisa e corpus da análise ..................................................25

3.3 - Procedimentos de coleta de dados e instrumentos empregados na coleta

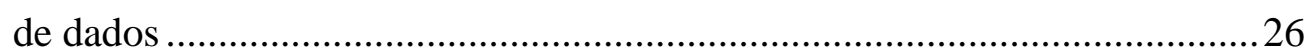

3.4 - Procedimentos de análise dos dados ...........................................................26

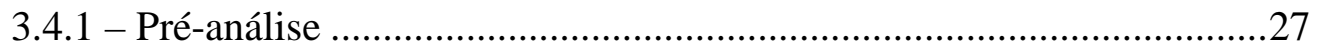

3.4.2 - Exploração do material ...................................................................28

3.4.3 - Tratamento dos resultados ................................................................ 
4.1 - Ações previstas no planejamento estratégico da UnB relacionadas com a Gestão de Recursos Humanos e ações de planejamento das Gerências de Recursos Humanos

4.2 - Comparação das ações de planejamento das Gerências de Recursos Humanos com informações constantes no Planejamento Estratégico da UnB.

4.3 - Diferenças verificadas quanto ao Plano de Desenvolvimento Institucional da UnB e as ações de planejamento das Gerências de Recursos Humanos

4.4 - Similaridades constatadas do Plano de Desenvolvimento Institucional da UnB e as ações do planejamento das Gerências de Recursos Humanos

CONSIDERAÇÕES FINAIS .50

REFERÊNCIAS .51

APÊNDICE A .53

APÊNDICE B .55 


\section{INTRODUÇÃO}

Nos dias atuais para manter-se no mercado é preciso utilizar diversas técnicas gerenciais para se destacar na concorrência, um deles é o planejamento estratégico que é um processo pelo qual a organização define seu caminho a longo prazo, na tentativa constante de alcançar seus objetivos. E esse posicionamento estratégico da empresa provoca o seu destaque no mercado, cada vez mais competitivo.

Quando o assunto é instituições públicas de ensino superior, nota-se o desafio desse tipo de organização em manter-se de modo sustentável na sociedade, pois na atualidade existe um número, cada vez mais crescente, de instituições particulares, que investem muito em estratégias para destacarem-se no mercado.

Estrada (2000 apud DELGADO FILHO; BASIC, 2004) reforça a conveniência de realizar planejamento estratégico em universidades, entretanto, diferentemente das organizações privadas, o planejamento estratégico nas universidades públicas precisa considerar alguns aspectos organizacionais e culturais típicos a essas universidades e apesar das diferenças existentes entre as empresas privadas e as instituições públicas, as características essenciais de organização de ambas tornam o conceito de planejamento estratégico aplicável às universidades, pois ele refere-se à necessidade de estabelecer sua missão, seu papel e os seus objetivos.

O planejamento estratégico em universidades públicas tem como objetivo recomendar que a gestão universitária tenha uma prática de gestão focada no planejamento de longo prazo, por isso institutos de ensino superior devem aprimorar sua administração e fazer uso mais eficiente dos recursos humanos e materiais disponíveis.

O planejamento estratégico é utilizado como instrumento de integração, a participação no pensamento estratégico da organização é mais importante do que o produto final, portanto, qualquer plano bem alinhado é melhor do que um bom plano sem o devido envolvimento (DELGADO FILHO; 2004).

Dessa forma, em qualquer tipo de organização que se realiza um planejamento estratégico, é preciso buscar o alinhamento das suas partes às diretrizes da estratégia adotada, o que, na maioria das vezes, possibilita um melhor desempenho das organizações. 


\section{1 - Contextualização do tema}

As técnicas administrativas visando ao planejamento empresarial se iniciaram na área financeira com o orçamento, que levou ao chamado planejamento a longo prazo, que consistia em uma extrapolação do orçamento para um maior número de anos, sem levar em conta mudanças ambientais. Com a visualização da necessidade de se alterar a direção da empresa, em função de mudanças ambientais, surgiu o planejamento estratégico, e mais recentemente os administradores visualizaram que a abordagem estratégica deveria ter uma abrangência maior na organização, não se atendo apenas a função do Planejamento, mas englobar as outras funções, como: organizar, dirigir e controlar, também a nível estratégico, de forma que procurasse a capacitação da empresa.

Ao longo da sua existência, as instituições de ensino têm conseguido sobreviver às mudanças do ambiente, recorrendo à sua capacidade de adaptação. Porém, enfrentam hoje um desafio, nas últimas décadas surgiu um conjunto de transformações que influenciam a vida e o comportamento destas instituições. Fenômenos como a massificação do ensino, as crescentes dificuldades de financiamento, a enorme diversidade de novas demandas por parte da sociedade, a emergência do mercado como um novo mecanismo regulador, os desafios das novas tecnologias, a alteração das relações com o governo levando a regimes que interferem na autonomia e ao aparecimento de sistemas de avaliação e as exigências da formação ao longo da vida geram enormes impactos sobre as instituições escolares.

Dentro desta diversidade de questões, o planejamento estratégico torna-se ponto crucial em qualquer Instituição, pois este engloba avaliar riscos e oportunidades, antecipar fatos, definir ações, ajustar a organização, forçar novas situações.

$\mathrm{Na}$ administração estratégica, busca-se que todas as áreas da empresa procurem a eficácia da organização como um todo e, para que isto aconteça, é necessário que a estratégia esteja presente em todas as áreas e não apenas na administração central ou em áreas operacionais, mas também em áreas de apoio, como o caso da área de Recursos Humanos.

A ênfase na gestão estratégica de recursos humanos é relativamente recente e originou-se nos Estados Unidos e na Inglaterra. A busca pelo alinhamento estratégico tem suas origens no aumento, cada vez maior, da competitividade global e na procura de vantagens competitivas sustentáveis (DYER; REEVES, 1995 apud ESTHER; PAÇOCUNHA; MACHADO, 2006).

Uma vez estabelecidos os objetivos e as estratégias para alcançá-los, o papel da área de Recursos Humanos é fundamental para a implementação do que foi planejado. Existe uma 
visão distorcida de que o Planejamento Estratégico é de responsabilidade exclusiva da Alta Administração, talvez porque as decisões estratégicas são tomadas a este nível, mas na realidade é necessária a participação de outros níveis da organização, de forma que o trabalho não fique distante da realidade, e para que, com o envolvimento de outros níveis na realização do plano possa ser mais fácil a sua implementação.

Portanto, a gestão de recursos humanos deve adotar um novo paradigma, focado na obtenção de resultados, sem descuidar das mudanças ocorridas no ambiente interno e externo da organização. Ao analisar a evolução da função de Recursos Humanos, percebe-se o deslocamento de uma atuação basicamente funcional para um papel mais estratégico, em que os gerentes de RH devem contribuir para os resultados e desenvolvimento da organização, e em consequência de uma visão holística, alinhar estrategicamente suas atividades ao negócio da empresa (LIPEC, 2001 apud ESTHER; PAÇO-CUNHA; MACHADO, 2006).

\section{2 - O problema de pesquisa}

No atual contexto das organizações em que as exigências da sociedade tornaram-se cada vez maiores, faz-se necessário que as empresas lutem por um espaço no mercado, uma forma disso acontecer é a formulação de estratégias, que estas sejam implantadas, não se tornem um discurso moderno, ou seja, a empresa deve ter pensamento e ações estratégicos (ESTHER; PAÇO-CUNHA; MACHADO, 2006).

Segundo Esther, Paço-Cunha e Machado (2006) para que tais ações e pensamentos causem efeitos na organização é preciso que exista uma articulação de todas as suas atividades, para que alcance os objetivos almejados, dentre essas atividades está a função de recursos humanos, pois se antigamente esta possui caráter burocrático e rotineiro, hoje, ela é revestida de um caráter estratégico.

Esther, Paço-Cunha e Machado (2006, p.1) afirmam ainda que "tendo em vista a evolução da função de recursos humanos ao longo do tempo, pressupõe-se que o alinhamento estratégico preconizado é uma das questões com que as empresas se deparam...”. Pode-se perceber então a necessidade e importância da gestão estratégica de recursos humanos, pois ela proporciona qualidade, produtividade, e, por conseguinte, competitividade das empresas (OLIVEIRA, 1999). 
Portanto, nesse contexto, não é possível as organizações terem a função de RH desalinhada com a estratégia geral, exigindo assim uma atuação mais incisiva e eficaz, tanto por parte da empresa quanto de seus profissionais.

O alinhamento estratégico pressupõe que áreas de apoio processual, como o Recursos Humanos, devem alinhar-se às estratégias da organização como um todo, assim, a gestão de RH deve possuir uma postura compatível com a estratégia que a organização adota (ESTHER; PAÇO-CUNHA; MACHADO, 2006).

Dessa forma, alinhamento estratégico pode ser definido como "a maximização da contribuição da área para criar vantagem competitiva sustentável, de modo a gerar valor" (BECKER; HUSELID; ULRICH, 2001 apud ESTHER; PAÇO-CUNHA; MACHADO, 2006, p.2). Segundo Schuler (1992 apud ESTHER; PAÇO-CUNHA; MACHADO, 2006) se ações da função de recursos humanos estiverem sistematicamente ligadas às necessidades estratégicas do negócio, pode-se afirmar que existe gestão estratégica de recursos humanos.

A partir do entendimento de tais conceitos, o presente trabalho poderá contribuir para análise do planejamento estratégico de $\mathrm{RH}$ da UnB para que transcendam a visão tradicional de planos. Tais estratégias devem subsidiar o aperfeiçoamento constante da gestão universitária, definir os caminhos que, seguidos, conduzirão ao engrandecimento da UnB e materializar os projetos e ações que representam proposta única, abraçada por toda a comunidade.

\section{3 - Definição da Pergunta de Pesquisa}

As pessoas que atuam nas gerências de Recursos Humanos percebem que as suas atribuições ou atividades de planejamento estão alinhadas aos objetivos do planejamento estratégico da Universidade de Brasília?

\section{4 - Objetivos}

\subsection{1 - Objetivo Geral}

Verificar na percepção das pessoas que compõem as Gerências de Recursos Humanos o alinhamento entre o planejamento estratégico da Universidade de Brasília e suas atividades de planejamento. 


\subsection{2 - Objetivos Específicos}

- Identificar as ações previstas no Planejamento Estratégico da UnB que estão relacionadas com a gestão de Recursos Humanos;

- Conferir as ações de planejamento das Gerências de Recursos Humanos;

- Comparar as ações de planejamento das Gerências de Recursos Humanos com as informações constantes no Planejamento Estratégico da UnB;

- Apontar diferenças verificadas quanto ao Plano de Desenvolvimento Institucional da UnB e as ações do planejamento das gerências de Recursos Humanos;

- Apontar similaridades constatadas do Plano de Desenvolvimento Institucional da UnB e as ações do planejamento das gerências de Recursos Humanos.

\section{5 - Justificativa}

Ao considerar fundamental que as organizações nos dias atuais busquem o alinhamento de todas as suas áreas ao planejamento estratégico, e que a área de recursos humanos pode ser um parceiro estratégico, desde que suas ações estejam orientadas dentro deste conceito, nota-se a importância deste estudo. Trata-se de um tema atual, que influencia na gestão da universidade.

A realização desta pesquisa tem o objetivo de contribuir para a melhoria da literatura pertinente, pois ao verificar o alinhamento das ações de planejamento das Gerências de Recursos Humanos ao planejamento estratégico da Universidade de Brasília é possível verificar se a atuação da Secretaria de Recursos Humanos da UnB está dentro desse contexto estratégico, contribuindo de forma eficaz para a gestão universitária.

O estudo encontra-se viável devido à fundamentação teórica e programação de tempo hábil para a pesquisa. Do ponto de vista financeiro, a pesquisa não depende de nenhum órgão de fomento à pesquisa. 


\section{2 - REFERENCIAL TEÓRICO}

Para compreender todo o processo do planejamento estratégico e possibilitar a visualização em relação do planejamento com a área de Recursos Humanos, a partir deste capítulo serão apresentados principais conceitos, definições e discussões sobre os temas: a) Planejamento: conceituação e tipos; b) Planejamento Estratégico; c) Gestão Estratégica Organizacional; d) Estratégia na área de Recursos Humanos; e) finalizando com a apresentação de outros estudos semelhantes desenvolvidos no tema.

\section{1. - Conceituação de planejamento}

Para Oliveira (1993) planejamento pode ser conceituado como um processo, desenvolvido para o alcance de uma situação desejada de forma mais eficiente e efetiva, com melhor concentração de esforços e recursos pela empresa, contudo, o planejamento estratégico corresponde ao estabelecimento de um conjunto de providências a serem tomadas pelo executivo para a situação em que o futuro tende a ser diferente do passado.

As organizações não trabalham na improvisação, o planejamento é para que sua atuação possa ser visualizada antecipadamente. Chiavenato (1993) aponta o planejamento com a primeira função administrativa, pois ele serve de base para as demais funções da administração, haja vista que nele estão previstos os objetivos que devem ser atingidos e como agir para alcançá-los, tornando-se um modelo teórico para a ação futura.

De uma forma mais simples, Chiavenato (1993) apresenta o planejamento como a definição dos objetivos e a escolha antecipada do melhor curso das ações para atingi-los, ou seja, o planejamento define onde se pretende chegar, o que deve ser feito, quando, como e em que sequiência. A Figura 1 mostra as premissas do planejamento: 


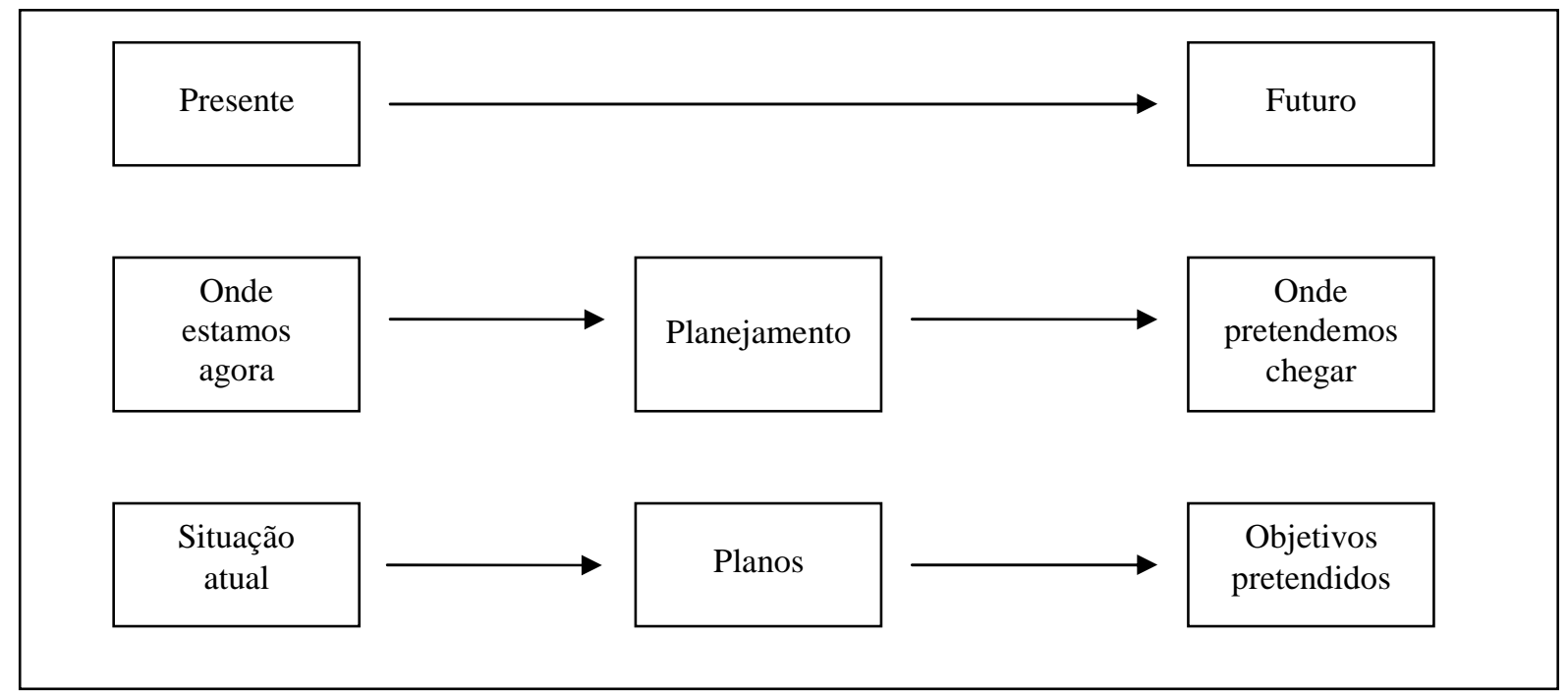

Figura 1: As premissas do planejamento Fonte: Chiavenato (1993, p. 252).

O planejamento começa com a fixação dos objetivos, que podem ser definidos como alvos que se pretendem alcançar dentro de certo espaço de tempo, aplicando-se determinados recursos disponíveis ou passíveis, ou seja, são pretensões que uma vez alcançadas passam a ser realidade (CHIAVENATO, 1993).

Os objetivos de uma organização são ordenados hierarquicamente, de acordo com a importância de cada um, portanto, podem ser desdobrados desde os objetivos globais até objetivos operacionais. Dessa maneira, Chiavenato (1993, p. 253) afirma que

O planejamento compõe-se tanto de estratégias a longo prazo por meio das quais se
pretende alcançar os objetivos globais da organização, como também de um
conjunto de planos detalhando as atividades cotidianas para o alcance dos objetivos
imediatos relacionados com uma divisão ou órgão da organização.
(CHIAVENATO, 1993, p. 253 ).

\subsection{1 - Tipos de planejamento}

Os tipos de planejamento são definidos de acordo com a hierarquia, ou seja, existem três níveis distintos: estratégico, tático e operacional. Dessa forma, os tipos de planejamento seguem esta estrutura: planejamento estratégico, planejamento tático e planejamento operacional (CHIAVENATO, 1993). 
Segundo Oliveira (1993) também define três tipos de planejamento, como descrito na Figura 2: operacionais, táticos e estratégicos, relacionando-os com os níveis de decisão numa pirâmide organizacional.

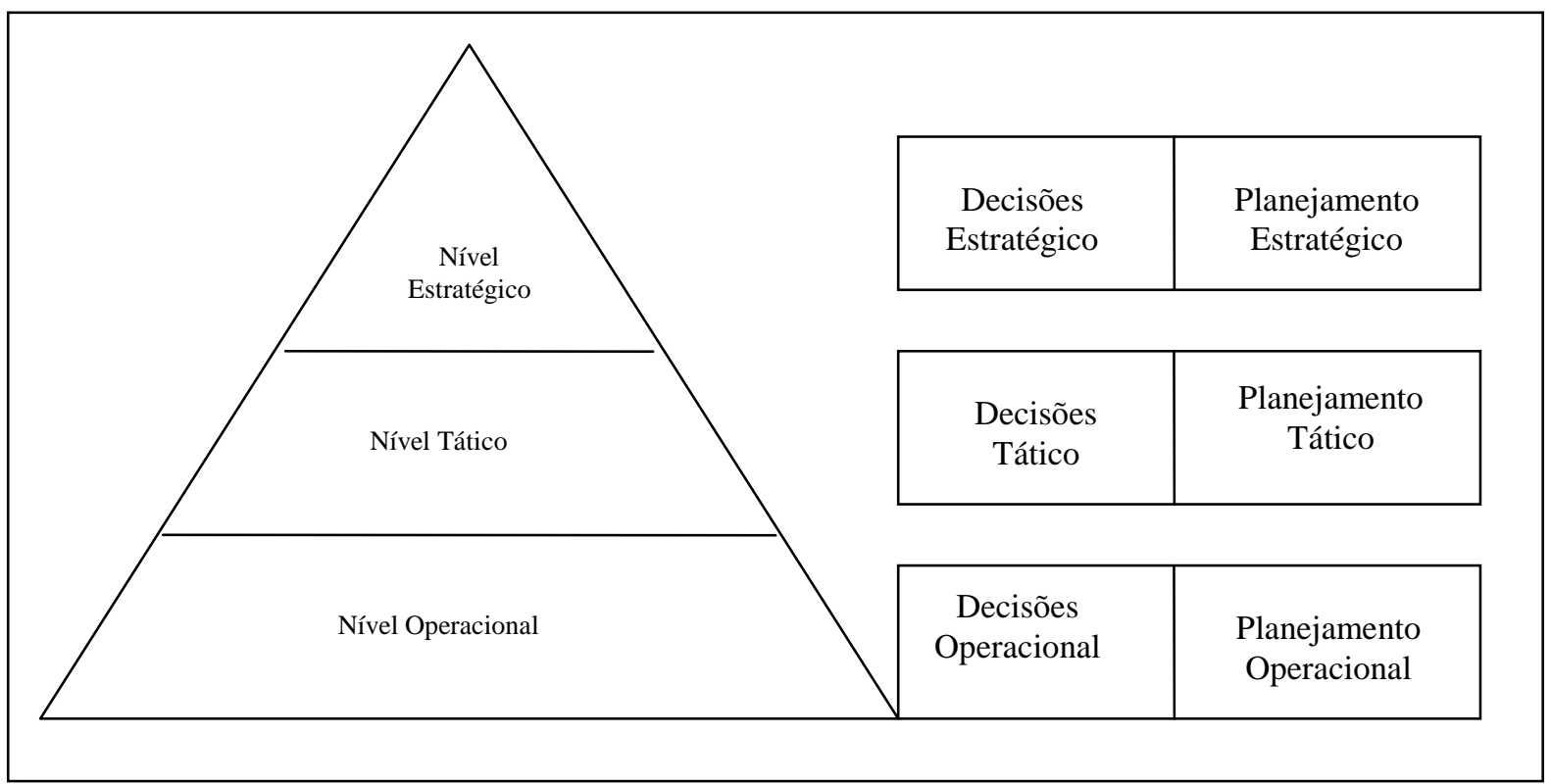

Figura 2: Níveis de decisão e tipos de planejamento.

Fonte: Oliveira (1991, p. 62).

Oliveira (1993) relata ainda que o planejamento deva considerar a empresa como um todo, e os vários tipos de planejamento existentes devem relacionar-se de forma integrada, sendo que esses apresentam diferenças básicas, quanto ao prazo, amplitude, riscos, atividades e flexibilidade.

Conforme Marcelino (2003) o que diferencia os planejamentos tático e operacional do planejamento estratégico é que este envolve toda a organização, enquanto que aqueles se referem a áreas específicas.

Para exemplificar, Oliveira (1993) apresenta alguns exemplos dos tipos de planejamento, de acordo com os níveis táticos, operacionais e estratégicos, conforme Quadro 1 a seguir: 


\begin{tabular}{|c|c|c|c|c|c|}
\hline \multicolumn{5}{|c|}{ Tipo } & \multirow{3}{*}{\begin{tabular}{l}
\multicolumn{1}{c}{ Nível } \\
Estratégico \\
Tático
\end{tabular}} \\
\hline \multicolumn{5}{|c|}{ Planejamento Estratégico } & \\
\hline $\begin{array}{l}\text { Planejamento } \\
\text { mercadológico }\end{array}$ & $\begin{array}{l}\text { Planejamento } \\
\text { Financeiro }\end{array}$ & $\begin{array}{l}\text { Planejamento } \\
\text { de Produção }\end{array}$ & $\begin{array}{l}\text { Planejamento } \\
\text { de Recursos } \\
\text { Humanos }\end{array}$ & $\begin{array}{l}\text { Planejamento } \\
\text { organizacional }\end{array}$ & \\
\hline $\begin{array}{l}\text { Plano de preços e } \\
\text { produtos }\end{array}$ & $\begin{array}{l}\text { Plano de } \\
\text { despesas }\end{array}$ & $\begin{array}{l}\text { Plano de } \\
\text { capacidade de } \\
\text { produção }\end{array}$ & $\begin{array}{l}\text { Plano de } \\
\text { recrutamento e } \\
\text { seleção }\end{array}$ & $\begin{array}{l}\text { Plano diretor de } \\
\text { sistemas }\end{array}$ & Operacional \\
\hline $\begin{array}{l}\text { Plano de } \\
\text { promoção }\end{array}$ & $\begin{array}{l}\text { Plano de } \\
\text { investimento }\end{array}$ & $\begin{array}{l}\text { Plano de } \\
\text { controle da } \\
\text { qualidade }\end{array}$ & $\begin{array}{l}\text { Plano de } \\
\text { treinamento }\end{array}$ & $\begin{array}{l}\text { Plano de } \\
\text { estrutura } \\
\text { organizacional }\end{array}$ & Operacional \\
\hline Plano de vendas & $\begin{array}{l}\text { Plano de } \\
\text { compras }\end{array}$ & $\begin{array}{l}\text { Plano de } \\
\text { estoque }\end{array}$ & $\begin{array}{l}\text { Plano de cargos } \\
\text { e salários }\end{array}$ & $\begin{array}{l}\text { Plano de rotinas } \\
\text { administrativas }\end{array}$ & Operacional \\
\hline $\begin{array}{l}\text { Plano de } \\
\text { distribuição }\end{array}$ & $\begin{array}{l}\text { Plano de fluxo } \\
\text { de caixa }\end{array}$ & $\begin{array}{l}\text { Plano de } \\
\text { utilização da } \\
\text { mão de obra }\end{array}$ & $\begin{array}{l}\text { Plano de } \\
\text { promoções }\end{array}$ & $\begin{array}{l}\text { Plano de } \\
\text { informações } \\
\text { gerenciais }\end{array}$ & Operacional \\
\hline $\begin{array}{l}\text { Plano de } \\
\text { pesquisas de } \\
\text { mercado }\end{array}$ & $\begin{array}{l}\text { Plano } \\
\text { orçamentário }\end{array}$ & $\begin{array}{l}\text { Plano de } \\
\text { expedição de } \\
\text { produtos }\end{array}$ & $\begin{array}{l}\text { Plano de } \\
\text { capacitação } \\
\text { interna }\end{array}$ & $\begin{array}{l}\text { Plano de } \\
\text { comunicações }\end{array}$ & Operacional \\
\hline
\end{tabular}

Quadro 1: Quadro dos tipos e níveis do Planejamento Estratégico

Fonte: Oliveira (1993, p.36).

Dessa forma, os tipos de planejamento podem ser definidos como (OLIVEIRA, 1993, p. 38):

1. Planejamento estratégico - é um processo gerencial que possibilita estabelecer o rumo a ser seguido pela organização;

2. Planejamento tático - tem por objetivo otimizar determinada área de resultado e não a empresa como um todo, por isso, trabalha com decomposições dos objetivos, estratégias e políticas estabelecidas no planejamento estratégico, uma de suas principais finalidades é a utilização eficiente de recursos disponíveis;

3. Planejamento operacional - trata-se dos planos de ação ou operacionais. 


\section{2 - Planejamento Estratégico}

O Planejamento estratégico surgiu nos anos 60 quando as forças que atuavam no mercado se tornavam cada vez mais imprevisíveis e inesperadas, forçando as organizações a buscarem novas formas de planejamento e gestão que lhes permitissem posicionar-se melhor num mercado cada vez mais competitivo. A essência do planejamento estratégico é produzir as estratégias necessárias para permitir enfrentar as mudanças ambientais.

Oliveira (1991 apud FARIAS; SENNA, 2008, p. 3) "define planejamento estratégico como um processo gerencial que possibilita ao executivo estabelecer o rumo a ser seguido pela empresa, com vistas a obter um nível de otimização na relação da empresa com o seu ambiente".

Segundo Melleiro, Tronchin e Ciampone (2005) o planejamento estratégico, também, pode ser visto como um importante instrumento que traz benefícios, auxiliando nas escolhas e na elaboração de planos que ajudam a enfrentar os processos de mudança, dessa forma, o planejamento estratégico é um conjunto de conhecimentos teóricos e práticos ordenados de modo a possibilitar a interação com a realidade, programar as estratégias e as ações necessárias, para alcançar os objetivos e as metas preestabelecidas.

Para Marcelino (1999 apud MARCELINO, 2003, p. 33) o planejamento estratégico “é um processo gerencial que possibilita ao dirigente público ou privado estabelecer o rumo a ser seguido pela organização, com o objetivo de obter um nível de adequação entre esta e seu ambiente."

Segundo Rocha (1999), o planejamento estratégico é um processo que tem início, meio e fim, sendo seu produto final o plano estratégico, tendo como principal objetivo idealizar, aprimorar, analisar, programar, monitorar e amparar estratégias que garantam vantagem competitiva à organização.

Por meio do planejamento estratégico a empresa espera: conhecer e melhor utilizar seus pontos fracos; conhecer e eliminar ou adequar seus pontos fracos; conhecer e usufruir as oportunidades externas e conhecer e evitar as ameaças externas (OLIVEIRA, 1993).

Para compreender melhor a noção do que sejam tais aspirações é necessário conceituar pontos fracos, pontos fortes, oportunidades e ameaças. O ponto forte é uma variável controlável pela organização, em que ela consegue uma diferenciação, esta oferece uma vantagem em seu ambiente, enquanto que o ponto fraco é uma situação inadequada que fornece uma desvantagem para a empresa no mercado, também é controlável. Já as oportunidades e ameaças estão no ambiente externo, por isso são incontroláveis pela 
organização, a oportunidade é uma força que pode favorecer a ação estratégica e a ameaça pode causar obstáculos à ação estratégica, mas que pode ser evitada (OLIVEIRA, 1993).

Para Oliveira (1993, p. 54) "a elaboração de um planejamento estratégico envolve a identificação das oportunidades e ameaças no ambiente externo da empresa e adoção de estimativas de risco para as alternativas estabelecidas", porém esta análise é feita após a identificação e avaliação dos pontos fortes e fracos da empresa, bem como a sua capacidade de tirar vantagens das oportunidades e enfrentar as ameaças.

Oliveira (1993) apresenta uma metodologia para a elaboração e implementação do planejamento estratégico, que é composta por quatro fases básicas: diagnóstico estratégico; missão da organização; instrumentos prescritivos e quantitativos; e controle e avaliação.

A fase de diagnóstico consiste em analisar a atual situação da organização, com base nas informações de seus ambientes interno e externo; a segunda fase destina-se a estabelecer a razão de ser da empresa, bem como o seu posicionamento estratégico. Os instrumentos prescritivos e quantitativos mostram como alcançar os objetivos desejados, a parte prescritiva relaciona-se com o estabelecimento dos objetivos, desafios e metas e estabelecimento de estratégias e políticas funcionais, enquanto que a parte quantitativa aborda as projeções econômico-financeiras. A última fase de controle e avaliação do planejamento busca acompanhar o desempenho da organização na busca de seus objetivos (OLIVEIRA, 1993).

De acordo com Marcelino (2003) o planejamento estratégico baseia-se na análise do meio ambiente, portanto, ao desenvolver suas diretrizes estratégicas se faz necessário que os cenários e possíveis mudanças no ambiente sejam consideradas. A essência do planejamento estratégico está na capacidade da organização de antecipar e determinar ações futuras, num ambiente de turbulência e incertezas.

Tendo em vista que o planejamento estratégico visa melhorar a relação organização e ambiente, que normalmente ocorre de forma turbulenta, Ansoff (1990 apud MARCELINO, 2003) indica como as principais causas para o desajuste entre uma organização e seu ambiente:

1. a agressividade do comportamento da organização - é preciso que essa adote uma postura mais agressiva a fim de aproveitar as oportunidades oferecidas pelo mercado;

2. a estratégica está de acordo com o ambiente futuro, mas a organização não possui potencialidade no presente; 
3. a organização elabora o planejamento estratégico sem considerar sua cultura interna, ou até mesmo sem promover as mudanças necessárias para a implementação dos planos.

\title{
2. 3 - Gestão Estratégica Organizacional
}

De acordo com Moraes (2004) o aumento da competitividade, a necessidade das empresas em apresentar resultados satisfatórios e a influência da globalização, têm levado as empresas a procurarem padrões de gerenciamento fundamentados nos conceitos de racionalização para a redução de custos, a estratégia organizacional incorporada adequadamente a essa busca auxiliam na otimização dos resultados.

O planejamento estratégico requer de seus gerentes não só previsibilidade, depois de formada a própria estratégia, mas também de acompanhamento e estabilidade durante sua implementação, portanto a gestão estratégica deve ser agregada ao planejamento.

Para Levy (1986 apud LEMOS et al., 2004, p. 3) "planejamento estratégico, juntamente com a cultura organizacional e arquitetura organizacional, integra a administração estratégica de uma empresa através da harmonia entre eles".

A gestão estratégica numa organização busca tornar significativa alguma característica própria, pois num mundo marcado pela incerteza, evolução tecnológica e o dinamismo da sociedade é preciso que as organizações busquem respostas estratégicas mais eficientes, já que a vantagem competitiva reside na criação e sustentação de uma diferença orientada à satisfação dos stakeholders, que são o grupo de pessoas e/ou organizações que possuem interesse na empresa (ESTEVÃO, 1998).

Desta forma, Estevão (1998, p. 5) define a gestão estratégica como

\begin{abstract}
Um processo global que visa a eficácia, integrando o planejamento estratégico (mais preocupado com a eficiência) e outros sistemas de gestão, responsabilizando ao mesmo tempo todos os gestores de linha pelo desenvolvimento e implementação estratégica; ela é um processo contínuo de decisão que determina a performance da organização, tendo em conta as oportunidades e ameaças com que esta se confronta no seu próprio ambiente, mas também as forças e fraquezas da própria organização. (ESTEVÃO, 1998, p.5)
\end{abstract}

Segundo Wright, Kroll e Parnell (2000, p. 25), em sentido amplo, a administração estratégica é "decisões e ações administrativas que auxiliam a assegurar que a organização formule e mantenha adaptações benéficas com seu ambiente". A administração estratégica é 
um termo abrangente, que aborda dentre esses aspectos outros como a determinação da missão e dos objetivos da organização no contexto de seus ambientes interno e externos, é possível ver a administração estratégica como uma série de passos em que algumas tarefas devem ser realizadas, como:

1. análise das oportunidades e ameaças ou limitações que existem no meio ambiente;

2. análise dos pontos fortes e fracos do ambiente interno;

3. estabelecimento da missão organizacional e dos objetivos gerais;

4. formulação das estratégias, que permita à organização combinar os seus pontos fortes e fracos com as oportunidades e ameaças do ambiente;

5. implementação das estratégias;

6. realização do controle estratégico.

Estevão (1998) apresenta um conjunto de características, que distingue a gestão estratégica de outros processos, sendo:

- é um processo integral, ou seja, consiste na combinação de todos os recursos da organização para obter-se vantagens competitivas;

- é contínua e interativa, pois se refere a uma série de etapas que são repetidas de forma cíclica, exigindo um reajustamento contínuo;

- proporciona um enquadramento que orienta a condução de outras fases de gestão;

- valoriza a flexibilidade e a criatividade, mantendo uma articulação interna de todos componentes e processos organizacionais;

- é difícil de realizar, pois é preciso aguardar os acontecimentos ou crises, para escolher alternativas;

- possibilita construir o futuro da organização, numa perspectiva de longo prazo.

Existe uma relação entre a gestão estratégica e os outros fatores que compõem a organização, como o planejamento estratégico, as necessidades de recursos, a estrutura e processos organizacionais e o controle estratégico (ESTEVÃO, 1998). A gestão estratégica é o eixo da roda que proporciona essa interação, conforme mostra a Figura 3: 


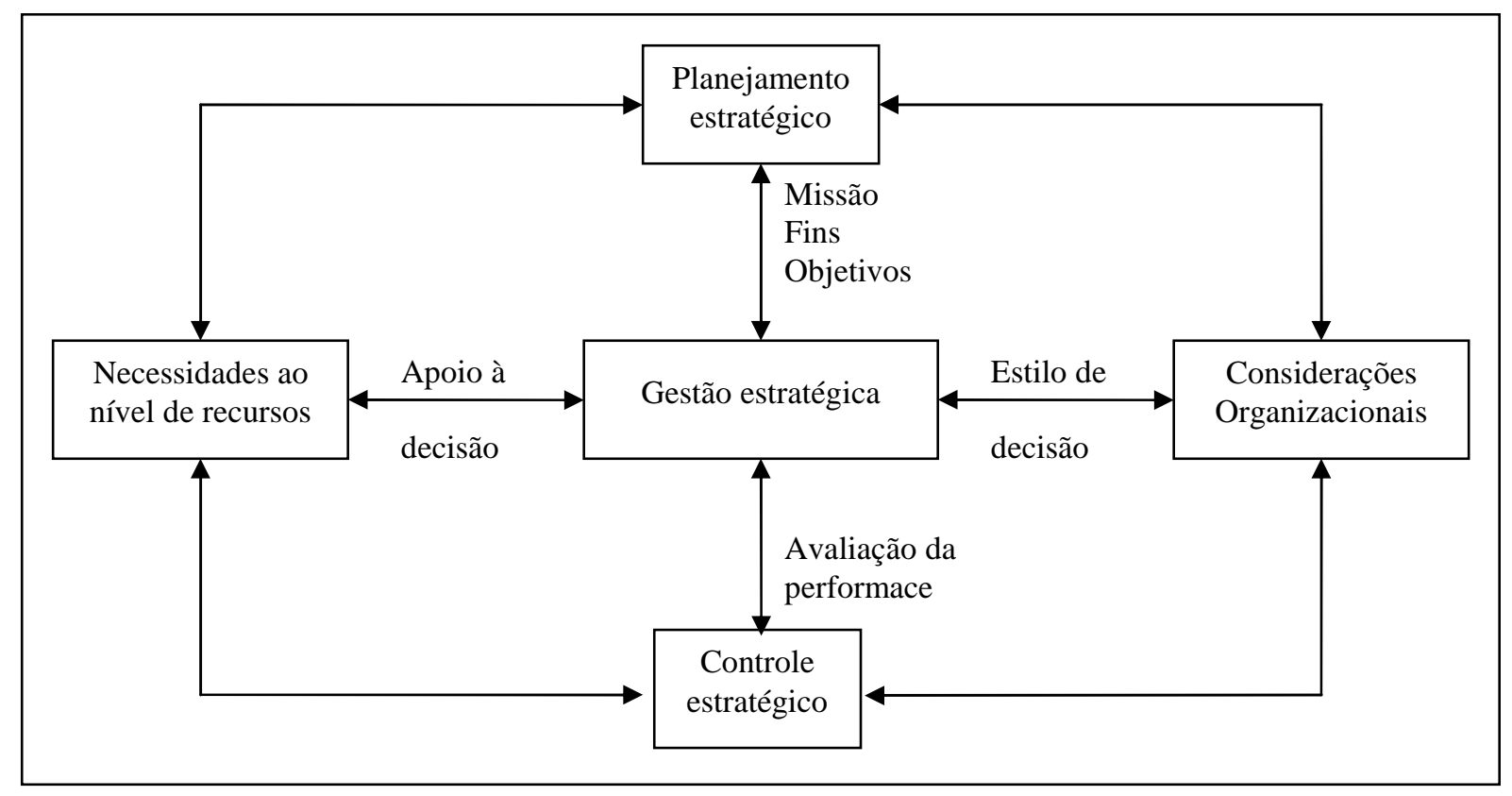

Figura 3: Diagrama dos 4 fatores estratégicos

Fonte: Rowe (1986 apud ESTEVÃO, 1998, p.7).

Cada um dos fatores mostrados acima exerce uma influência sobre a gestão estratégica, os recursos são fundamentais para apoiar as decisões do gestor, o planejamento estratégico se apresenta essencial para a definição da missão e dos objetivos, e o fator organizacional e o controle estratégico interfere no estilo da decisão e na avaliação (ESTEVÃO, 1998).

Para compreender melhor o conceito de gestão estratégica, faz-se necessário o entendimento do que seja a estratégia, esta "refere-se aos planos da alta administração para alcançar resultados consistentes com a missão e os objetivos gerais da organização", em si, a estratégia envolve três partes, sendo:

1. a formulação da estratégia - consiste na elaboração e desenvolvimento dessa;

2. a implementação da estratégia - trata-se de colocar a estratégia em ação;

3. o controle estratégico - refere-se ao acompanhamento à estratégia, podendo modificá-la ou ajustá-la, para assegurar que os resultados pretendidos sejam alcançados.

Oliveira (1991) afirma que o conceito básico de estratégia está relacionado à ligação da organização ao seu ambiente, e dentro dessa interação procura-se definir e operacionalizar estratégias que maximizam os seus resultados, sendo que a finalidade das estratégias é estabelecer os caminhos, os cursos e os programas de ação que devem ser seguidos para 
alcançar os objetivos planejados, de forma a utilizar adequadamente os recursos físicos, financeiros e humanos, com foco na maximização das oportunidades do ambiente e minimização dos problemas.

Dessa forma, Oliveira (1991, p.27) conceitua a estratégia como "o ajustamento da empresa ao seu ambiente, em forma geral em constante mutação, quase sempre com a empresa alterando suas próprias características, tendo em vista este ajustamento". Estevão $(1998$, p.2) relata que

A noção de estratégia está ligada a qualquer processo de tomada de decisões que afete toda a organização por um prazo temporal dilatado; constitui, assim, um conjunto de decisões e de ações que têm por finalidade assegurar a coerência interna e externa da organização, mobilizando todos os seus recursos. (ESTEVÃO, 1998, p. 2)

Segundo Estevão (1998) a gestão está tradicionalmente muito ligada ao planejamento, tornando-se uma das principais funções do gestor, entretanto, a natureza do planejamento evoluiu de uma visão que inicialmente se preocupava com questões orçamentais, para a acentuação de perspectivas mais sofisticadas que ampliaram os horizontes e realçaram a capacidade de visão.

Para Mintzberg (1994 apud ESTEVÃO, 1998, p.2) “o planejamento se apresenta como um processo baseado na análise que deve acompanhar a estratégia", com função de controlar e coordenar as ações para o alcance dos objetivos, enquanto que a estratégia se baseia na síntese e reflete sobre o que está na base de vantagem competitiva de uma organização. Segundo Wright, Kroll e Parnell (2000, p. 35)

\footnotetext{
As decisões estratégicas, por sua própria natureza, são caracterizadas por risco e incerteza consideráveis. Mudanças rápidas e amplamente imprevisíveis podem transformar rapidamente mesmo os planos mais concebidos em estratégias ineficazes. A maioria dos tomadores de decisão reconhece claramente esse perigo e aprende a conviver com ele. (WRIGHT; KROLL; PARNELL, 2000, p. 35)
}

Wright, Kroll e Parnell (2000) apresentam um modelo do processo de administração estratégica. O primeiro passo é a análise de oportunidades e ameaças, em seguida o ambiente interno também é analisado, haja vista que a missão e objetivos da organização são definidos de acordo com o contexto das oportunidades, ameaças, pontos fortes e pontos fracos.

A formulação de estratégias nos três níveis da organização, estratégico, tático e operacional, é orientada de acordo com os objetivos gerais e a missão. Posteriormente as estratégias são implementadas através da estrutura organizacional, lideranças, distribuição de poder e cultura. A última etapa desse processo é o controle estratégico, que visa melhorar o 
desempenho. A Figura 4, abaixo, mostra o Modelo de Administração Estratégica apresentado por Wright, Kroll e Parnell (2000) e auxilia a visualização do processo.

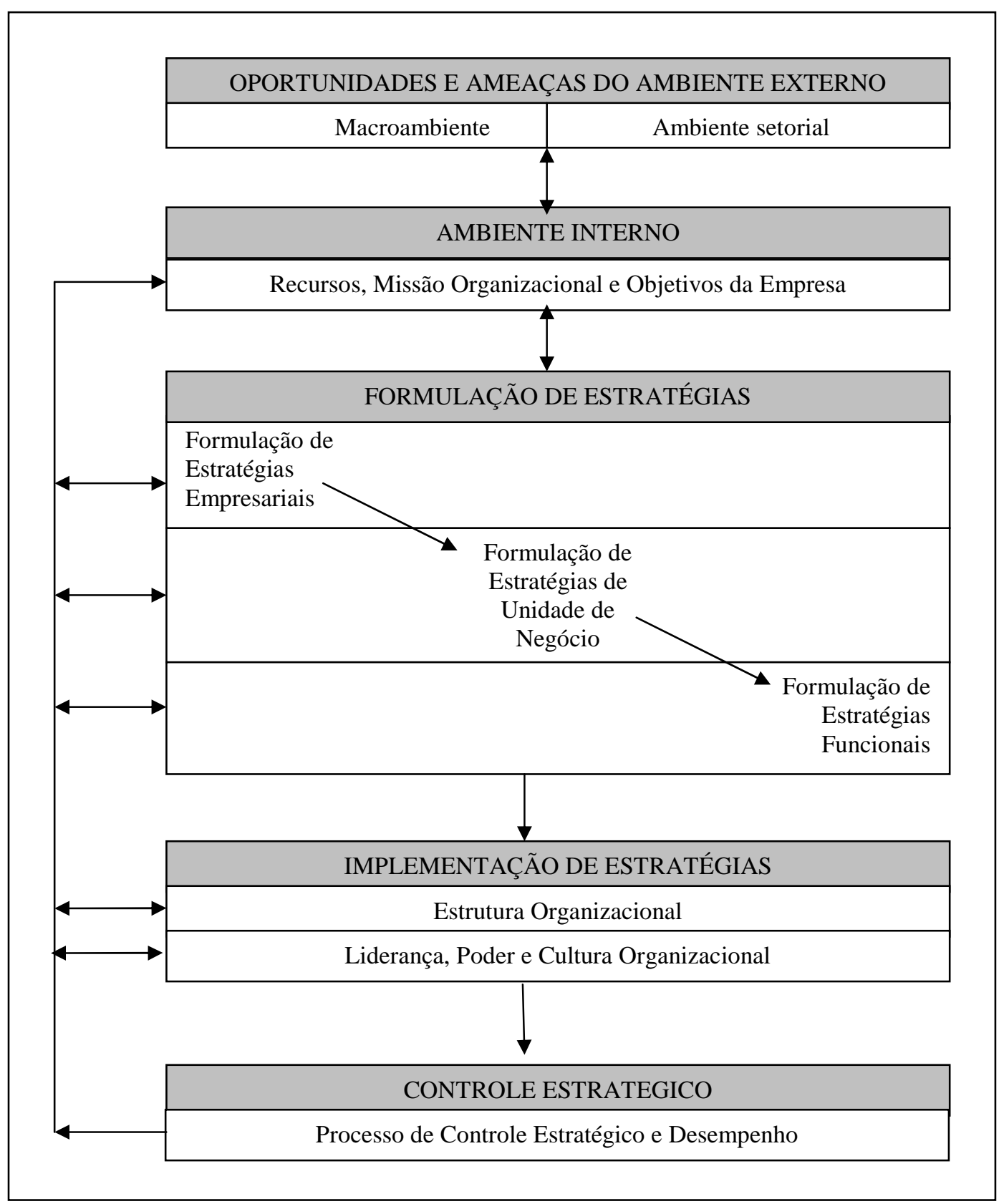

Figura 4: Modelo de Administração Estratégica

Fonte: WRIGHT, KROLL e PARNELL (2000, p.366).

Depois que as estratégias são implementadas, estas podem sofrer modificações, ou seja, de acordo com as mudanças ocorridas nas condições ambientais ou organizacionais é preciso que se adaptem as estratégias à nova realidade e necessidade da organização, este fato caracteriza a administração estratégica como um processo contínuo. 
Wright, Kroll e Parnell (2000, p. 37, 38) afirmam que

\begin{abstract}
(...) uma estratégia pretendida (o que a administração originalmente planejou) pode ser realizada em sua forma original, em uma forma modificada ou até mesmo em uma forma completamente diferente. Ocasionalmente, é claro, a estratégia pretendida pela organização é implementada, mas normalmente a estratégia pretendida e a estratégia realizada (o que a administração implementa na realidade) diferem. A razão disso é que ocorrem eventos ambientais ou organizacionais não previstos que provocam mudanças na estratégia pretendida. (WRIGHT; KROLL; PARNELL, 2000, p. 37,38)
\end{abstract}

A gestão estratégica traz, aos indivíduos de uma organização, não só um perfil de seu ambiente externo e interno, como promove a sistematização do caminho a ser seguido pela empresa, pautados nestas análises. O planejamento estratégico é a principal ferramenta para uma efetiva gestão estratégica, já que neste planejamento, a organização mapeia seus planos, objetivos e metas, em longo prazo, pautados na missão da empresa.

\title{
2.4 - Estratégia na área de Recursos Humanos
}

Depois de estabelecidos os objetivos e as estratégias o papel da área de Recursos Humanos é fundamental para a implementação do que foi planejado, por isso as políticas de RH devem estar de acordo com as estratégias da organização, pois a organização é um conjunto de pessoas que trabalham para satisfazer as suas necessidades, faz-se necessário que o interesse das pessoas esteja orientado para atender aos objetivos organizacionais (ANSOFF 1977 apud ALMEIDA 1993).

Almeida (1993, p. 23) “considera a administração estratégica de recursos humanos como um processo de gestão onde as decisões estratégicas seriam aquelas ligadas aos investimentos para a maximização do crescimento do capital humano".

Segundo Souza (2005 apud FARIAS; SENNA, 2008, p.4) "o talento intelectual de uma empresa é um importante elemento de competitividade e que o talento de uma empresa é a soma de seus talentos individuais", dessa forma pode-se perceber a relevância de incluir a área de recursos humanos nas estratégias da organização, tornando-se assim um recurso estratégico.

Para Dessler (2003 apud FARIAS; SENNA, 2008, p.5) "as estratégias estão cada vez mais dependentes da formação de equipes de trabalho comprometidas", esse fato faz com a área de Gestão de Pessoas desempenhe um papel de destaque no planejamento estratégico da organização (FARIAS; SENNA, 2008, p.5). 
Farias e Senna (2008, p. 2) afirmam que

\begin{abstract}
As grandes empresas hoje têm focado na educação corporativa de seus colaboradores e investido nas pessoas como diferencial para garantir sua competitividade. Esse fator justifica a preocupação em criar planos estratégicos para as áreas de Gestão de Pessoas alinhados aos objetivos organizacionais. (FARIAS; SENNA, 2008, p. 2)
\end{abstract}

Dentro desse contexto, Alburquerque (1999 apud ESTHER; PAÇO-CUNHA; MACHADO, 2006, p. 3) aponta que "a gestão de recursos humanos deve adotar um novo paradigma centrado na obtenção de resultados, conciliando preocupações relativas ao ambiente externo e ao ambiente interno."

Com o objetivo de alinhar a função de recursos ao posicionamento da organização, algumas ações são importantes, como: inserção dos recursos humanos na gestão estratégica; criação de ambiente propício a mudanças e aprendizagem organizacional; gestão da cultura organizacional e constituição e fortalecimento do trabalho em equipe (SANTOS; CARPINETTI; GONÇALVES, 1997 apud ESTHER; PAÇO-CUNHA; MACHADO, 2006).

Para Ulrich (1998 apud ESTHER; PAÇO-CUNHA; MACHADO, 2006) a administração de estratégias de RH visa ajustá-las à estratégia empresarial, nessa linha, é proposto o alinhamento estratégico para a área de $\mathrm{RH}$, visto que esta passa a ser vista como um parceiro estratégico da organização e um agente de mudanças.

\title{
2.5 - Estudos semelhantes desenvolvidos sobre o tema
}

A importância do alinhamento da organização ao seu planejamento estratégico é um tema relevante nos estudos direcionados à área de estratégia, uma vez que este proporciona mais eficácia às estratégias da organização, tendo sido foco de várias pesquisas sobre o assunto.

Esther, Paço-Cunha e Machado (2007) desenvolveram um estudo de caso numa grande empresa do setor de embalagens, titulado de "Alinhamento estratégico da gestão de recursos humanos: o caso de uma grande empresa de embalagens". O trabalho em questão tinha como objetivo analisar e discutir até que ponto a gestão de recursos humanos pode contribuir para a vantagem competitiva da empresa, sob a ótica dos gerentes. 
Foi feito um estudo de caso e as informações foram obtidas por meio de entrevistas semi-estruturadas com cinco dos seis gerentes e com o coordenador da área de recursos humanos na empresa pesquisada, também foi feita a análise dos documentos institucionais fornecidos e do site da empresa.

Com o estudo percebeu-se que devido à busca constante da empresa pela certificação da qualidade o seu pensamento estava mais voltado para a eficiência e não para a eficácia, dessa forma as gerências visavam alcançar as metas, mais por uma questão de formalidade do que uma questão efetivamente estratégica.

Outro fato relevante é que a organização em análise não possuía uma diretriz estratégica clara e negociada para a gestão de recursos humanos, portanto, a função de RH não contribuía efetivamente para a competitividade da empresa, embora esta tenha conseguido destacar no mercado sem o devido alinhamento estratégico.

Farias e Senna (2007), realizaram um estudo qualitativo numa instituição bancária de médio porte e instalada no Distrito Federal que objetivou identificar os principais fatores restritivos ao alinhamento da Gestão de Pessoas à estratégica organizacional, na ótica dos gerentes de área.

A pesquisa desenvolvida foi descritiva e para a coleta de dados foram utilizadas técnicas de entrevista e análise documental de alguns documentos da empresa, como Manual do Planejamento Estratégico, documentos históricos dos planos estratégicos, plano estratégico e planos de ações da empresa, dentre outros e estudo de caso da instituição bancária.

A entrevista, semi-estruturada, com roteiro, era composta por dezesseis perguntas, que seguiam ordem lógica entre os assuntos e aprofundamento gradativo nos temas relativos ao planejamento estratégico de Gestão de Pessoas. Foram entrevistadas, individualmente, seis gerentes da área de RH e para análise dos dados foi utilizada a técnica de análise de conteúdo.

No estudo verificou-se que a empresa já trabalhava com planos estratégicos há vários anos, no entanto, as pessoas do nível gerencial atestaram desconhecimento dos indicadores e metas estratégicas, nesse caso, recomendou-se a realização de trabalhos de integração e sensibilização com as gerências de Recursos Humanos, para que a percepção do pessoal de RH modifique e enriqueça, por conseguinte, alinhar o planejamento estratégico à função de RH.

Marcelino (2002) também realizou um estudo sobre o processo de planejamento estratégico. A pesquisa foi com um órgão do Palácio do Planalto, a Secretaria-Geral da Presidência da República (SGPR/PR), e do seu braço executivo, a Diretoria-Geral de 
Administração (DGA). O processo iniciou-se em 1995, com a realização de dois Encontros de Planejamento e Administração Estratégica, tendo como propósito identificar a missão e os objetivos, formularem as estratégias e estabelecer programas e projetos prioritários para o quadriênio 1995-1998.

A metodologia utilizada neste estudo foi especialmente desenvolvida pelo próprio autor para o setor público brasileiro, tendo como pressupostos básicos o incentivo à criatividade individual, a participação e o comprometimento dos agentes envolvidos e a busca do consenso do grupo.

Tal metodologia foi desenvolvida em três partes:

1) os participantes utilizaram a técnica de brain-writing (geração de idéias), trabalhando individualmente, com formulários previamente estruturados, gerando idéias por escrito; é uma técnica de grupo nominal;

2) o grupo nominal se transformou em grupo real de trabalho, no qual as idéias foram discutidas em busca do consenso do grupo, utilizando as técnicas tradicionais de dinâmica de grupo;

3) aconteceu um debate no grande grupo (plenária) e consenso sobre o tema, tendo como base as contribuições dos pequenos grupos.

Como resultado final desse processo de planejamento estratégico e reestruturação da DGA, o quadro dos servidores foi reduzido de 1.187, em janeiro de 1995, para 742 servidores, em dezembro de 1998, uma redução de $37 \%$ do efetivo pessoal, permitindo ainda melhorar, substantivamente, a qualidade nas atividades desenvolvidas, uma distribuição da força de trabalho mais adequada, apesar da redução dos efetivos de pessoal, e uma estrutura mais compatível com as demandas.

Neste estudo verificou-se que a escolha do modelo mais adequado de planejamento e estruturação de uma organização é necessariamente contingencial e depende do ambiente, da natureza da atividade e da tecnologia, dos objetivos e estratégias da organização e das pessoas envolvidas, possibilitando atender às solicitações da sociedade por maior eficácia e eficiência na gestão pública. 


\section{3 - METODOLOGIA}

A metodologia visa mostrar como ocorrerá todo o processo de investigação do estudo. Neste capítulo será apresentado o tipo de pesquisa realizada, a população e amostra da pesquisa, os procedimentos de coleta de dados e os procedimentos de análise dos dados.

\section{1 - Tipo de Pesquisa}

A pesquisa realizada na Secretaria de Recursos Humanos da Universidade de Brasília foi do tipo descritiva, quanto aos fins. Vergara (2007) define a pesquisa descritiva como a pesquisa que mostra as características da população em estudo ou de determinado fenômeno, podendo estabelecer correlações entre variáveis e definir a natureza dessas, e não possui o dever de explicar os fenômenos em estudo, mas serve de base para elaborar explicações sobre tais fenômenos. Quanto à perspectiva temporal em relação à coleta de dados, tratou-se de um estudo transversal, isto é: a coleta de dados ocorreu de uma só vez, em um único período de tempo. Porém, quanto à perspectiva temporal de análise, pode-se dizer que a análise dos planos PDI's no período de 2006 a 2010 lhe dão um caráter longitudinal de análise.

Trata-se de uma pesquisa qualitativa, uma vez que este estudo fez uma análise qualitativa das informações obtidas nas entrevistas. Richardson et al (1999, p. 90) caracterizam esse tipo de pesquisa como "a tentativa de uma compreensão detalhada dos significados e características situacionais apresentadas pelos entrevistados".

Quanto aos meios de investigação classifica-se como pesquisa documental e estudo de caso. A pesquisa documental é investigação "realizada em documentos conservados no interior de órgãos públicos e privados de qualquer natureza, ou com pessoas" (VERGARA, 2007, p. 48). O estudo de caso para Gil (1999 apud FARIAS; SENNA, 2008) refere-se a uma análise aprofundada e exaustiva, que possibilita conhecer de forma ampla e detalhada o objeto em estudo. 


\section{2 - Os sujeitos da pesquisa e corpus de análise}

Para Vergara (2007) os sujeitos da pesquisa são as pessoas que fornecerão os dados que o pesquisador necessita. Neste estudo de caso foram entrevistados seis gerentes da Secretaria de Recursos Humanos da Universidade de Brasília, uma vez que Richardson et al (1999) recomendam que a entrevista não seja feita a mais de 20 pessoas, pois cada uma oferece um material riquíssimo para a análise, exigindo assim um tempo considerável do pesquisador para a realização da análise.

Os sujeitos desta pesquisa foram seis gerentes de RH que têm poder de decisão e respondem pelas seguintes Gerências: Gerência de Capacitação; Gerência de Cadastro Funcional; Gerência de Concurso, Ingresso e Movimentação; Gerência de Desempenho Funcional; Gerência de Aposentadoria e a Gerência do Núcleo Especializado em Segurança do Trabalho.

O critério de seleção dos gerentes entrevistados fundamentou-se no Ato da Reitoria n. 1011 de 30 de abril de 1997, que estabelece a estrutura básica da Secretaria de Recursos Humanos. Tendo em vista que o gerente da Gerência de Pagamento não se prontificou em conceder entrevista, foi selecionada a gerente da Gerência de Aposentadoria para substituição do mesmo. Apesar de a Gerência de Aposentadoria não constar do Ato da Reitoria citado, bem como outras novas gerências existentes na Secretaria de Recursos Humanos, optou-se pela mesma pelo fato de a gerente estar na função há mais de três anos e constatado a existência de ações previstas do PDI a serem alcançadas.

Quanto a gênero três entrevistados eram do sexo feminino e três do sexo masculino, sendo que quatro tinham idade acima de 43 anos. Apenas dois tinham cargo em nível superior e os demais em nível médio. Três deles tinham até 15 anos de UnB e os outros três tinham de 20 a 29 anos, onde apenas dois exerceram função de gerência anteriormente. Dos seis entrevistados, um exerce função de gerência há 15 anos na Instituição e os demais exercem há menos de 10 anos.

Os seis gerentes entrevistados foram codificados como G1, G2, G3, G4, G5 e G6, para fins de exposição dos resultados e análise dos dados preservando sua identificação isoladamente. 


\section{3 - Procedimentos de coleta de dados e instrumentos empregados na coleta de dados}

Primeiramente foi realizada uma pesquisa documental, que teve como corpus de texto, documentos tais como Bases do Planejamento Estratégico e Tático 2006-2010, o Manual de Planejamento 2006-2010 e o Plano de Desenvolvimento Institucional (PDI).

Nos itens 1 - Identificar as ações previstas no Planejamento Estratégico da UnB que estão relacionadas com a gestão de Recursos Humanos e 2 - Conferir as ações de planejamento das Gerências de Recursos Humanos, dos objetivos específicos, somente a análise documental foi suficiente para o alcance dos resultados pretendidos. Para os demais itens 3 - Comparar as ações de planejamento das Gerências de Recursos Humanos com as informações constantes do Planejamento Estratégico da UnB, 4 - Apontar diferenças verificadas quanto ao Plano de Desenvolvimento Institucional da UnB e as ações do planejamento das gerências de Recursos Humanos e 5 - Apontar similaridades contatadas do Plano de Desenvolvimento Institucional da UnB e as ações do planejamento das gerências de Recursos Humanos, tanto a análise documental quanto as entrevistas realizadas com os gestores da área serviram de corpus de texto para análise de conteúdo realizada neste estudo.

Com os seis gerentes da SRH foi feita uma entrevista pessoal, semi-estruturada que “caracteriza-se por um roteiro básico, não rígido, podendo ser adaptado pelo entrevistador de acordo com o andamento e interações com os entrevistados" (LÜDKE; ANDRÉ, 1986 apud FARIAS; SENNA, 2008, p.7).

As entrevistas foram realizadas no mês de fevereiro de 2009, de forma individual e foram gravadas, mediante autorização dos sujeitos entrevistados, com duração média de 20 a 30 minutos. Após realização das mesmas, foram transcritas de forma fiel as informações dos entrevistados, categorizadas e analisadas com base na técnica de análise do conteúdo.

O roteiro da entrevista era composto por doze questões, conforme Apêndice A, desta monografia e foi elaborado visando destacar três áreas: 1) área responsável pelo planejamento estratégico da Instituição; 2) participação da SRH no planejamento estratégico e 3 ) percepção dos gerentes quanto ao alinhamento das políticas e práticas da SRH ao PDI.

\section{4 - Procedimento de análise de dados}

As análises das Bases do Planejamento Estratégico e Tático e do Plano de Desenvolvimento Institucional da UnB buscaram identificar os elementos estratégicos e os 
objetivos institucionais da Universidade, bem como os elementos orientadores das áreas estratégicas, em especial da Área de Recursos Humanos. O Manual de Planejamento 2006-2010 teve como objetivo explicar o funcionamento do Sistema de Planejamento por meio dos instrumentos de planejamento e acompanhamento, bem como mostrar a elaboração dos Planos Plurianuais e Relatórios Trimestrais.

As informações obtidas foram classificadas de acordo com as três áreas identificadas no roteiro da entrevista, e foram analisadas à luz dos conceitos apresentados no referencial teórico.

Desta forma, para a análise dos dados foi utilizada a análise de conteúdo, que Bardin (1979 apud RICHARDSON, 1999, p. 223) define como

Um conjunto de técnicas de análise das comunicações visando obter, através
de procedimentos sistemáticos e objetivos de descrição do conteúdo das
mensagens, indicadores (quantitativos ou não) que permitam inferir
conhecimentos relativos às condições de produção/recepção (variáveis
inferidas) dessas mensagens (BARDIN, 1979 apud RICHARDSON, 1999, p.
223).

Segundo Richardson et al (1999, p. 224) a análise de conteúdo é mais utilizada para estudar materiais do tipo qualitativo, pois permite compreender melhor um discurso. Sendo este um estudo qualitativo justifica-se a adoção da técnica de análise de conteúdo. Para Bardin (1977 apud FARIAS; SENNA, 2008) a análise de conteúdo possui três fases, sendo:

\subsection{1 - Pré-análise}

Consiste em juntar os materiais da organização e transcrever as entrevistas realizadas.

Entre as atividades recomendadas por Bardin (1977 apud FRANCO, 2007), para serem realizadas nessa etapa, podem-se destacar:

a) A leitura "Flutuante" - contato inicial com o material, para conhecer a estrutura da narrativa, ter as primeiras orientações e impressões em relação à mensagem dos documentos.

b) A escolha dos documentos - o objetivo poderá ser determinado pelo pesquisador e, por conseguinte, convém escolher o universo de documentos adequados para fornecer informações sobre o problema levantado. 
Os itens de pesquisa deste estudo estão representados nos objetivos específicos, esperando-se encontrar tais questões no decorrer da discussão dos resultados encontrados.

\subsection{2 - Exploração do material}

Segundo Richardson et al (1989), procede-se à análise propriamente dita. Trata-se de uma fase longa e cansativa, consistindo basicamente na codificação, categorização e quantificação da informação.

Para categorização das entrevistas foi utilizada a metodologia proposta por Flick (2004 apud SENNA, 2007) chamada Codificação Temática. Para esse autor a codificação temática é muito usual em estudos comparativos. O emprego desse método foi considerado pertinente, tendo em vista que essa pesquisa visou identificar o alinhamento estratégico na visão dos Gerentes em RH da UnB.

Posteriormente a transcrição das entrevistas, foi realizada uma breve descrição de cada entrevista em forma de estudo de caso, conforme orientação metodológica de Flick (2004 apud SENNA, 2007), e depois de descritas, foi utilizada codificação aberta e seletiva para estabelecimento de categorias.

Conforme Flick (2004 apud SENNA, 2007, p. 42), codificação aberta "objetiva expressar dados e fenômenos na forma de conceitos". Esse procedimento visa a identificação da definição subjetiva do entrevistado em relação ao assunto tratado na pesquisa.

Nesse estudo foram considerados todos os parágrafos e levantados códigos (palavras ou seqüência de palavras que representassem conceitos dos conteúdos das falas dos entrevistados) e categorias para cada entrevista. Concluída essa fase, desempenhou-se a codificação seletiva onde se organizaram as "categorias essenciais em torno das quais outras categorias desenvolvidas" (FLICK 2004 apud SENNA, 2007, p.43), pudessem ser agrupadas.

Diante do exposto, para cada categoria criada a seguir, foram utilizadas as perguntas correspondentes ao questionário aplicado aos entrevistados.

As perguntas 1 - Antes de assumir a função atual, o (a) senhor (a) fez algum tipo de curso que o (a) preparasse para assumi-lo? Quais? e 2 - O (A) senhor (A) já assumiu ou substituiu outras funções de gerências anteriormente? Quais?, não foram incluídas nas categorias porque se referem ao perfil dos entrevistados. 


\begin{tabular}{|c|c|}
\hline CATEGORIAS & PERGUNTAS DO QUESTIONÁRIO \\
\hline $\begin{array}{l}1 \text { - Conhecimento das metas da SRH no } \\
\text { PDI }\end{array}$ & $\begin{array}{l}\text { 3- O Plano de Desenvolvimento Institucional } \\
\text { - PDI é o documento que contém o plano } \\
\text { estratégico da universidade de Brasília - } \\
\text { UnB para } 2006 \text { a 2010. O (A) senhor (a) } \\
\text { como gerente, conhece as metas } \\
\text { estabelecidas para a Secretaria de Recursos } \\
\text { Humanos - SRH neste documento? Quais? }\end{array}$ \\
\hline $\begin{array}{l}2 \text { - Parceria da SRH e planejamento } \\
\text { estratégico }\end{array}$ & $\begin{array}{l}4 \text { - O (A) senhor (a) considera a gestão da } \\
\text { SRH como um parceiro no planejamento das } \\
\text { metas estabelecidas para o Plano de } \\
\text { Desenvolvimento Institucional da UnB? Por } \\
\text { quê? } \\
5 \text { - Em sua opinião de que forma ocorre a } \\
\text { parceria "Gestão SRH e Plano de } \\
\text { Desenvolvimento Institucional da UnB"? }\end{array}$ \\
\hline $\begin{array}{l}3 \text { - Participação da SRH no planejamento } \\
\text { estratégico }\end{array}$ & $\begin{array}{l}\text { 6- Como ocorre a participação da SRH no } \\
\text { processo de planejamento estratégico da } \\
\text { UnB? } \\
7-\text { O (A) senhor (a) identifica a participação } \\
\text { e contribuição das atividades executadas na } \\
\text { sua gerência nos objetivos institucionais da } \\
\text { UnB? } \\
11 \text { - Qual a importância do plano de } \\
\text { desenvolvimento institucional da UnB no } \\
\text { planejamento das metas da SRH? }\end{array}$ \\
\hline $\begin{array}{l}4 \text { - Relação entre as atividades executadas e } \\
\text { o PDI da UnB }\end{array}$ & $\begin{array}{l}\text { 8 - Na sua opinião, existe uma relação entre } \\
\text { as atividades executadas na sua gerência e os } \\
\text { objetivos do Plano de Desenvolvimento } \\
\text { Institucional da UnB? }\end{array}$ \\
\hline $\begin{array}{l}5 \text { - Relação de equipe de trabalho e o } \\
\text { planejamento estratégico da UnB }\end{array}$ & $\begin{array}{l}9 \text { - O (A) senhor conscientiza sua equipe de } \\
\text { trabalho sobre a importância das atividades } \\
\text { executadas na gerência para o planejamento } \\
\text { estratégico da UnB? } \\
10 \text { - De que forma o (a) senhor (a) faz } \\
\text { esforços para que a sua equipe de trabalho se } \\
\text { conscientize e trabalhe com foco nos } \\
\text { objetivos da SRH? }\end{array}$ \\
\hline $\begin{array}{l}\text { 6- Participação da gerência no } \\
\text { planejamento da UnB }\end{array}$ & $\begin{array}{l}12 \text { - Fale um pouco sobre a participação da } \\
\text { sua gerência no planejamento estratégico da } \\
\text { UnB. }\end{array}$ \\
\hline
\end{tabular}




\subsection{3 - Tratamento dos resultados}

O tratamento dos resultados é a interpretação das informações, atribuindo-lhes significados.

Segundo Richardson (1984), a análise de conteúdo visa a um tratamento quantitativo que não exclui a interpretação qualitativa.

Desta maneira, Bardin (2004 apud SENNA, 2007), pontua que a partir do tratamento dado às respostas dos indivíduos, ou seja, a descrição das mensagens, são feitas inferências sobre esses dados, que por último serão interpretados. Sendo assim, interpretam-se as informações conferindo-lhe significados às características descritas. 


\section{4 - APRESENTAÇÃO E DISCUSSÃO DOS RESULTADOS}

Nesse capítulo serão apresentados e discutidos os resultados encontrados na análise documental e nas entrevistas, sendo a discussão baseada na fundamentação teórica desse estudo. Os resultados serão prestados conforme a ordem dos objetivos específicos apresentados na introdução dessa pesquisa.

\section{1 - Ações previstas no planejamento estratégico da UnB relacionadas com a gestão de Recursos Humanos e ações de planejamento das Gerências de Recursos Humanos}

Nesses dois primeiros objetivos específicos, a análise documental foi de grande valia, pois foi verificado que a Universidade elaborou dois documentos de suma importância para o alcance do seu planejamento estratégico: Bases do Planejamento Estratégico e Tático e o Manual de Planejamento 2006-2010.

Conforme a apresentação referente ao primeiro documento foi constatada que o diagnóstico realizado pelos gestores universitários e a discussão interna sobre os elementos constituíram as Bases do Planejamento Estratégico e Tático que trouxeram a definição do Plano Plurianual da FUB e da UnB para o período de 2006 a 2010. Este documento sintetiza as sugestões enviadas e oferece à discussão da comunidade universitária e dos colegiados superiores das Instituições uma proposta de trabalho para o quinquênio.

Pode-se verificar que o ciclo de planejamento foi iniciado em 2006 e após análise pelos gestores em suas unidades, a Administração Superior discutiu os elementos e sugestões apresentados e definiu os elementos básicos do Planejamento Estratégico da FUB/UnB: a Missão, o Negócio, os Princípios, a Visão e, os seis objetivos, descritos a seguir, que orientaram o desenvolvimento de ações e projetos da Universidade e de suas unidades acadêmicas e administrativas. O plano institucional foi definido, em todos os níveis, tendo por base metas e indicadores para avaliar o desempenho da Universidade e de todas as suas unidades.

Objetivos Estratégicos da UnB:

Formar pessoas com alta qualificação científica, tecnológica e artística, comprometidas com o bem-estar social, adaptáveis às mudanças e capazes de promover inovações e de se manterem atualizados ao longo do tempo; 
$\checkmark$ Garantir condições e mecanismos que permitam alcançar a excelência, ampliar a produção científica e gerar conhecimento adequado às necessidades da sociedade;

$\checkmark$ Implantar política de valorização, ampliação e consolidação da extensão universitária;

$\checkmark$ Implementar políticas de apoio, integração e bem-estar da comunidade universitária;

$\checkmark$ Ter quadro permanente de pessoal qualificado suficiente para o desenvolvimento da Instituição e

$\checkmark$ Implementar modelo de gestão que viabilize a infra-estrutura e a sustentabilidade institucional.

Diante desse contexto foi possível observar que é pertinente a colocação do autor Chiavenato (1993), conforme Figura 1, constante do Capítulo 2, subitem 2.1, onde o mesmo apresenta o planejamento como a definição dos objetivos e a escolha antecipada do melhor curso das ações para atingi-los, ou seja, o planejamento define onde se pretende chegar, o que deve ser feito, quando, como e em que sequência.

O Planejamento Tático da Universidade, realizado por Decanos, Secretários e suas equipes, teve como primeira atividade analisar a consistência de metas e indicadores estratégicos. Em seguida foram definidas as dez áreas de atuação que viabilizaram a implementação de processo de modernização da gestão universitária: Ensino de Graduação, Pós-Graduação, Pesquisa, Extensão, Assuntos Comunitários, Recursos Humanos, Planejamento e Gestão, Espaço Físico e Obras, Comunicação Institucional e Tecnologia da Informação e, por fim, foram definidos os objetivos, diretrizes, metas e indicadores que orientaram o desenvolvimento da Universidade, das Áreas e das unidades acadêmicas e administrativas (Bases do Planejamento Estratégico e Tático, 2007, p. 9).

Os resultados dos trabalhos desenvolvidos foram divulgados junto à comunidade universitária e discutidos no Conselho Universitário. Simultaneamente, as unidades foram convidadas a elaborar seus Planos Plurianuais. Coube à Secretaria de Planejamento orientar os gestores na elaboração de seus planos plurianuais e consolidá-los no Plano Quinquenal da UnB: 2006 a 2010. Este Plano contém os elementos do Plano de Desenvolvimento Institucional para o mesmo período e da versão preliminar dos Planos Anuais de Atividades dos próximos anos. 
Verificou-se que, a base estratégica da UnB compreende as seguintes diretrizes:

Missão da UnB: produzir, integrar e divulgar conhecimento, formando cidadãos comprometidos com a ética, a responsabilidade social e o desenvolvimento sustentável.

$\checkmark$ Negócio da UnB: conhecimento

$\checkmark$ Princípios da UnB: ética e respeito à diversidade; autonomia institucional com transparência e responsabilidade social; busca permanente de excelência; universalização do acesso; respeito à dignidade, à liberdade intelectual e às diferenças e preservação e valorização da vida.

$\checkmark$ Visão: alcançar padrão de excelência acadêmica e ser referência nacional, contribuindo para o desenvolvimento econômico e social do País.

Ainda no documento Bases do Planejamento Estratégico e Tático, encontramos as descrições quanto às diretrizes para a área de Recursos Humanos, as quais foram definidas de acordo com o diagnóstico ambiental deste setor, conforme Apêndice B - Quadro 1. As diretrizes são:

Visão da Área de Recursos Humanos - ser Instituição pública de referência nacional na gestão de recursos humanos motivados, qualificados, comprometidos com a qualidade das atividades acadêmicas e da gestão transparente e ética.

Perspectivas da UnB Área de Recursos Humanos - disporá de quadro de pessoal corretamente dimensionado, em termos qualitativo e quantitativo; terá pessoal com remuneração adequada, em termos de mercado, e digna; implantará sistemas e processos institucionais integrados, atualizados e com interface mais amigável e terá planos de carreira devidamente implementado e consolidado.

$\checkmark$ Desafios Estratégicos da Área de Recursos Humanos - superar a insuficiência de recursos humanos; vencer a limitação de recursos orçamentários e financeiros; elaborar propostas visando a racionalizar a legislação federal sobre recursos humanos e corrigir a falta de integração de sistemas, a defasagem tecnológica e a inadequação da estrutura organizacional. 
O Manual de Planejamento da UnB é o documento que demonstra as características do Sistema de Planejamento da UnB, apresenta as suas bases e especifica as etapas a serem cumpridas pelos gestores para elaborar, acompanhar e atualizar os seus planos. Ele é dividido em três partes, sendo que a primeira descreve as bases desse Sistema, a segunda parte orienta os gestores universitários na elaboração dos planos das unidades ao Plano Plurianual da UnB e a terceira, orienta a elaboração dos Relatórios Trimestrais e do Relatório Anual de Gestão.

De acordo com o Manual de Planejamento da UnB o processo de planejamento abrange os níveis estratégico, tático e o operacional. O Planejamento Estratégico, elaborado pela Administração Superior, define os objetivos a serem alcançados, a longo e médio prazos, pelas unidades integrantes do Sistema de Planejamento. No Planejamento Operacional, os planos elaborados são detalhados anualmente, configurando as metas a serem alcançadas em cada um dos projetos elaborados.

A arquitetura do Sistema de Planejamento da UnB é representada pela Figura 5 a seguir.

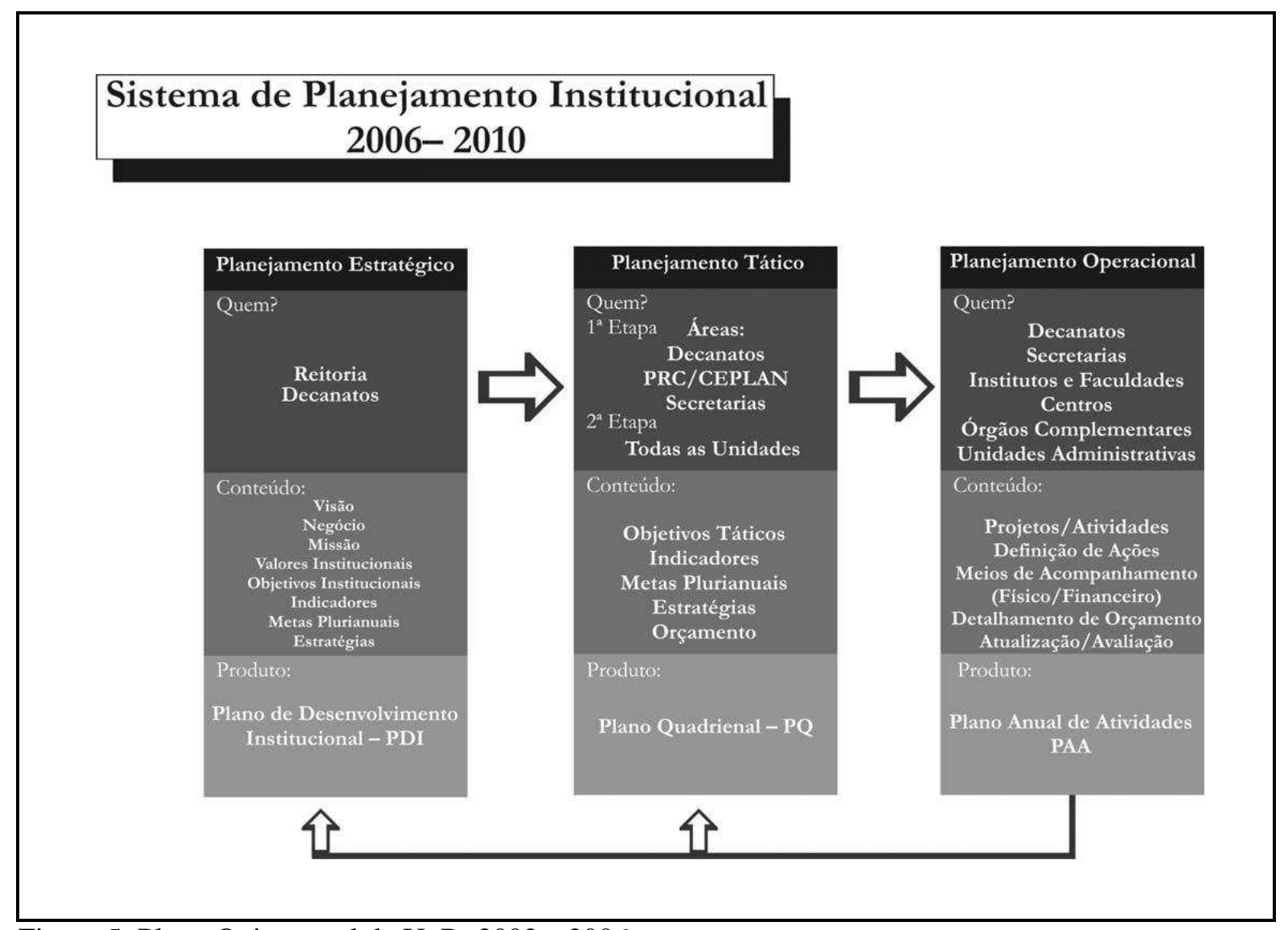

Figura 5: Plano Quinquenal da UnB: 2002 a 2006

Fonte: Manual de Planejamento da UnB (2007, p.10) 
Observando os documentos acima mencionados ao definir os objetivos referentes ao planejamento estratégico da UnB, pode-se relacionar com a afirmação de Chiavenato (1993, p.253) ao dizer que

O planejamento compõe-se tanto de estratégias a longo prazo por meio das quais se pretende alcançar os objetivos globais da organização, como também de um conjunto de planos detalhando as atividades cotidianas para o alcance dos objetivos imediatos relacionados com uma divisão ou órgão da organização. (CHIAVENATO, 1993, p. 253).

O Sistema de Planejamento Institucional contém as propostas de atuação da Universidade de Brasília e da Fundação Universidade de Brasília, sua mantenedora. Ele abrange os planos estabelecidos para um ciclo de planejamento quinquenal, coincidindo o último ano do ciclo, com o primeiro ano de um Reitorado (Manual de Planejamento, 2007, p. 11).

A elaboração dos planos institucionais é descrita na Figura 6:

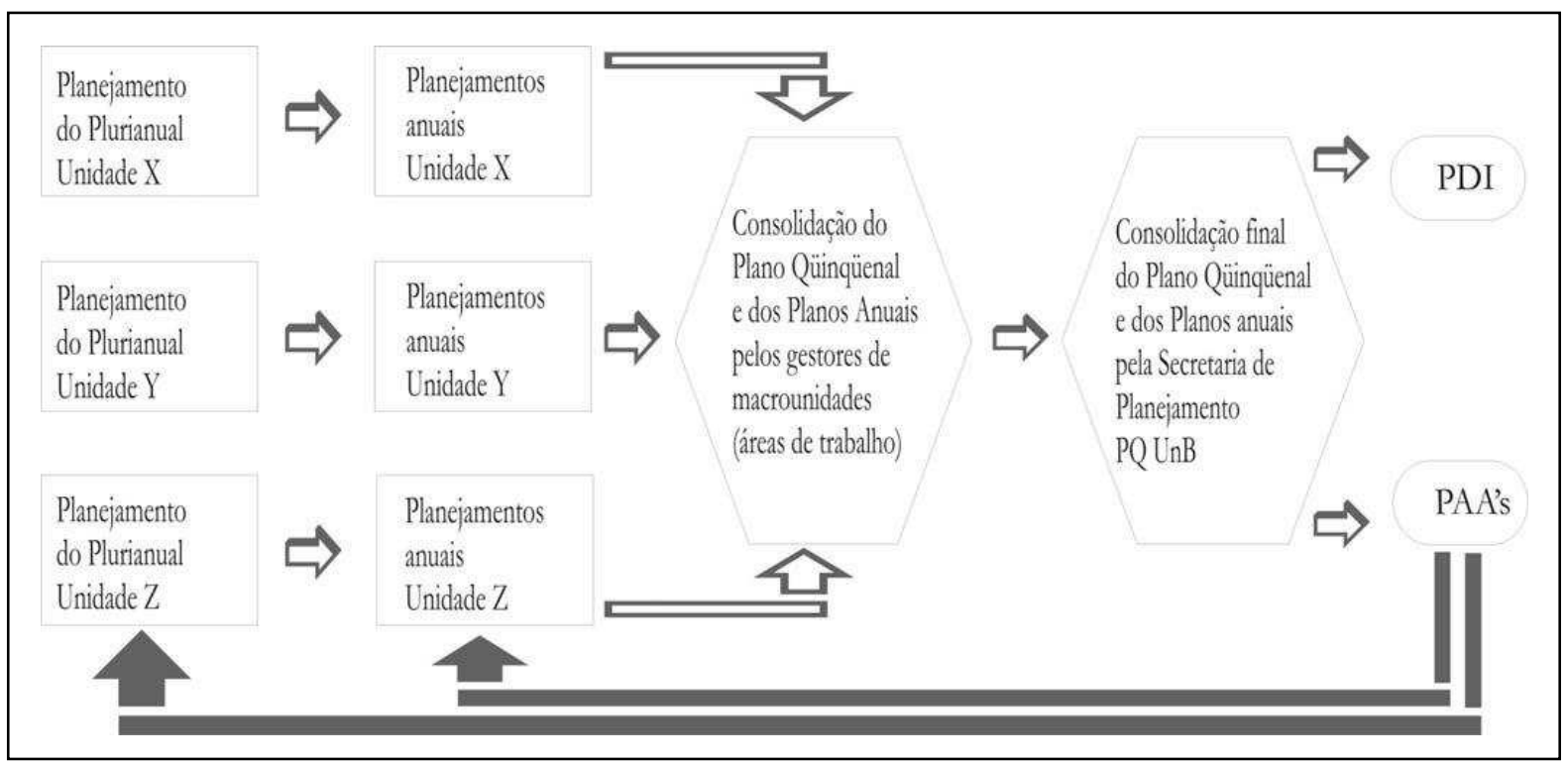

Figura 6: Ciclo Quinquenal de Acompanhamento e Avaliação do Sistema de Planejamento e dos Planos

Fonte: Manual de Planejamento da UnB (2007, p.11) 
Conforme consta do Manual de Planejamento (2007), o Sistema de Planejamento da UnB conta com nove instrumentos: cinco relacionados à elaboração, à atualização e ao acompanhamento dos planos institucionais elaborados pelas unidades administrativas e acadêmicas e quatro associados à avaliação das atividades desenvolvidas, tanto pelas unidades, quanto pela Instituição.

São instrumentos associados à elaboração do Planejamento Institucional e das unidades acadêmicas e administrativas:

a) Plano de Desenvolvimento Institucional - PDI: contém as definições estratégicas da UnB e as metas a serem alcançadas a longo prazo. Serve de elemento orientador do planejamento institucional e como instrumento de divulgação, junto à comunidade e a órgãos externos, dos principais objetivos a serem alcançados. Deve ser aprovado pelo Conselho Universitário da UnB e pelo Conselho Diretor da FUB.

b) Plano Quinquenal (PQ): contém os projetos apresentados por todas as unidades. Esses projetos estão associados aos objetivos institucionais e metas institucionais de longo prazo, sendo geridos institucionalmente pelos responsáveis pelas dez áreas em que se estrutura o acompanhamento do planejamento a médio e longo prazos. No PQ, os projetos e metas plurianuais das unidades são detalhados em períodos anuais que permitem o acompanhamento e replanejamento dos projetos e atividades propostos. O Plano Quinquenal deve ser aprovado pelas mesmas instâncias do PDI e sua operacionalização deve ser o elemento-chave na elaboração dos orçamentos anuais.

c) Plano Anual de Atividades (PAA): consiste no detalhamento de objetivos e metas previstos para cada ano. Sua primeira versão é elaborada simultaneamente ao PDI e ao PQ da Instituição. Ao final de cada exercício, a avaliação e a reestruturação do $\mathrm{PQ}$ permitem a atualização dos Planos Anuais subseqüentes. $\mathrm{O}$ PA do primeiro exercício do Qüinqüênio é utilizado na definição da linha de financiamento dos projetos aprovados pelas unidades. As mudanças subsequientes são acompanhadas pela Câmara de Administração e Finanças (CAF) da UnB.

d) Matriz de Planejamento: documento sintético usado para garantir a consistência das bases do planejamento estratégico da UnB. Serve como orientador na classificação dos projetos idealizados pelas unidades, em relação à proposta global da Universidade. 
e) Matriz de Indicadores Institucionais: essa matriz deve contem os indicadores gerais relativos aos objetivos e áreas de planejamento institucional. Os indicadores permitirão a avaliação da performance das diversas unidades, garantindo a homogeneidade de avaliação às diversas unidades integrantes do Sistema de Planejamento da Universidade.

São instrumentos associados ao acompanhamento da UnB e suas Unidades:

a) Relatórios Trimestrais de Planejamento (RTP): são instrumentos elaborados pelas cinqüenta e duas unidades envolvidas no planejamento. Esses relatórios são cumulativos e identificam o grau de alcance das metas anuais definidas pelas unidades; o volume de recursos despendidos no desenvolvimento dos projetos elaborados; os entraves institucionais ao desenvolvimento das atividades; as medidas corretivas sugeridas pelos gestores finalistas a serem adotadas pela Administração Superior. Esse instrumento permite que seja acompanhada a arrecadação de cada unidade, as atividades desenvolvidas por meio das fundações de apoio existentes e, ainda, o volume de renúncia de receita assumido pela UnB, na execução de suas atividades.

b) Relatório Anual de Gestão: é elaborado com base no último Relatório Trimestral de Avaliação do exercício e consiste em avaliação institucional do grau de alcance do planejamento executado pelas unidades individualmente e pela Universidade como um todo. Dele consta, além do acompanhamento das atividades relacionadas ao ensino, à pesquisa e à extensão, a avaliação da evolução do patrimônio e dos projetos estratégicos definidos pela Fundação Universidade de Brasília (FUB).

c) Seminário de Planejamento: deve ser realizado no terceiro ano do período de planejamento, com o objetivo de analisar a harmonia e consistência entre o planejamento e a execução plurianual, de promover a atualização ou revalidação do diagnóstico estratégico institucional, e, finalmente, de identificar as possíveis macro correções a serem feitas no processo de planejamento, a longo prazo. 
d) Relatório de Avaliação Plurianual: ao final do quinquênio, deverá ser elaborado Relatório circunstanciado onde serão analisados os objetivos e metas alcançados, a evolução da Linha de Financiamento, ao longo do período de planejamento, a consistência e adequação dos instrumentos e indicadores e, definidas as mudanças gerais a serem implementadas. As referidas mudanças ocorrerão em dois níveis: no do sistema de planejamento, contemplarão os conceitos, áreas, instrumentos e indicadores adotados; no da organização, serão definidos novos objetivos e metas globais por unidades.

De acordo com o Manual de Planejamento, além disso, as Instituições Federais de Ensino são obrigadas a elaborar Planos de Desenvolvimento Quinquenais que definam os objetivos e metas institucionais a serem cumpridos. A última norma legal que contém a obrigatoriedade de elaboração do Plano de Desenvolvimento Institucional é o Decreto $\mathrm{n}^{\circ}$ 5.773, de 9 de maio de 2006. O Ministério da Educação detalha os elementos que integram este Plano no endereço http://www2.mec.gov.br/sapiens/pdi.html.

Ainda no Manual de Planejamento, as normas observadas da FUB (Lei 3.998 de 15.12.1961) e da UnB (Estatuto da Universidade de Brasília - Decreto n ${ }^{\circ} 500$ de 15.10.1962) enfatizam, também a importância de estabelecer Planos que orientem o desenvolvimento da Universidade de Brasília.

Ao analisar os documentos descritos para elaboração do planejamento estratégico da UnB, verifica-se que é condizente a afirmação de Oliveira (2003) ao relatar que o planejamento deve considerar a empresa como um todo, e os vários tipos de planejamento existentes devem relacionar-se de forma integrada, sendo que esses apresentam diferenças básicas, quanto ao prazo, amplitude, riscos, atividades e flexibilidade.

É pertinente também a colocação de Marcelino (2003) sobre o assunto, ao afirmar que, o que diferencia os planejamentos tático e operacional do planejamento estratégico é que este envolve toda a organização, enquanto que aqueles se referem a áreas específicas.

Foi possível, desta forma, identificar também que a metodologia utilizada pela Instituição é semelhante à proposta de Oliveira (1993), conforme Quadro 1, constante do Capítulo 2, subitem 2.1.1, que define os tipos de planejamento, sendo: 
1. planejamento estratégico - como visto anteriormente, é um processo gerencial que possibilita estabelecer o rumo a ser seguido pela organização;

2. planejamento tático - tem por objetivo otimizar determinada área de resultado e não a empresa como um todo, por isso, trabalha com decomposições dos objetivos, estratégias e políticas estabelecidas no planejamento estratégico, uma de suas principais finalidades é a utilização eficiente de recursos disponíveis;

3. planejamento operacional - trata-se dos planos de ação ou operacionais.

\section{2 - Comparação das ações de planejamento das gerências de Recursos Humanos com as informações constantes no Planejamento Estratégico da UnB}

Nesta etapa serão consideradas as três categorias que respondem ao objetivo específico quanto à comparação das ações de planejamento das gerências de Recursos Humanos com as informações constantes no Planejamento Estratégico da UnB.

Estas categorias referem-se ao conhecimento das gerências em relação às metas da SRH no PDI da UnB, percepção dos gerentes quanto à parceria da SRH e o planejamento estratégico da Instituição, e ainda a participação e a importância da SRH no planejamento estratégico da Universidade.

$\mathrm{Na}$ categoria 1 percebe-se que todos os gerentes afirmaram ter conhecimento das metas da SRH no PDI da UnB, porém ficou evidente, conforme se pode verificar nos relatos a seguir, que eles não aplicam totalmente o que consta do documento de rotina das suas atividades.

\footnotetext{
"Não detalhadamente. Alguma coisa eu conheço, mas não detalhadamente. Conheço, mas superficialmente. Conheço mais nas áreas específicas da minha Gerência (...), coisas assim...no geral".
}

(Entrevistado G4)

“Conheço algumas. Olha, agora no momento não". 


\begin{tabular}{|c|l|}
\hline Entrevistados & \multicolumn{1}{|c|}{ Categoria 1 - Conhecimento das metas da SRH no PDI da UnB } \\
\hline G1 & $\begin{array}{l}\text { "Algumas. Não me recordo assim de todas porque tivemos uma reunião no começo do } \\
\text { ano passado, em 2008, com a Cristina1, que nos passou as diretrizes, que por acúmulo de } \\
\text { trabalho, ou coisa assim, não li mais sobre o PDI, mas procuro assim, estar } \\
\text { desenvolvendo... algumas regras...as regras estabelecidas na Universidade para } \\
\text { cumprimento das metas do PDI." }\end{array}$ \\
\hline G2 & $\begin{array}{l}\text { "Sim, inclusive já participei do Plano Plurianual e também tive um conhecimento sobre o } \\
\text { desenvolvimento das atividades da gerência de Recursos Humanos". }\end{array}$ \\
\hline G3 & $\begin{array}{l}\text { "Conheço. (...)". } \\
\text { G4 }\end{array}$ \\
\hline G5 & $\begin{array}{l}\text { "Não detalhadamente. Alguma coisa eu conheço, mas não detalhadamente. Conheço, } \\
\text { assim...no geral". } \\
\text { "Sim, conheço. Reuniões, talvez reuniões semestrais ou anuais, é colocado aberto para } \\
\text { que todos os gerentes participem nas suas áreas em relação a este plano". }\end{array}$ \\
\hline G6 & "Conheço algumas. Olha, agora no momento não". \\
\hline
\end{tabular}

Quadro 2: Categoria Conhecimento das metas da SRH no PDI da UnB

Fonte: Pesquisa de campo, 2009.

Essas afirmações mostram que os gerentes da SRH, parece não conhecerem o planejamento estratégico desenvolvido para a área de $\mathrm{RH}$ de forma objetiva, talvez, pela pouca divulgação do PDI pela Secretaria de Planejamento da UnB. Para Moraes (2004) o planejamento estratégico requer de seus gerentes não só previsibilidade, depois de formada a própria estratégia, mas também de acompanhamento e estabilidade durante sua implementação, portanto a gestão estratégica deve ser agregada ao planejamento.

Para Levy (1986 apud LEMOS et al., 2004, p. 3) "planejamento estratégico, juntamente com a cultura organizacional e arquitetura organizacional, integra a administração estratégica de uma empresa através da harmonia entre eles”.

Na categoria 2, observa-se que todos os gerentes demonstram dificuldades em atender aos objetivos constantes do documento que estabelece o planejamento estratégico da UnB.

Nota-se que tais dificuldades acontecem pelos seguintes motivos apontados: trabalho individualizado de cada setor, a falta de reuniões periódicas com o Secretário Geral da SRH e a colocação de obstáculos, pelos gerentes, para atender ao PDI, como por exemplo, a falta de servidores do quadro, limitações externas e limitação financeira, conforme podemos verificar nos relatos abaixo:

\footnotetext{
${ }^{1} \mathrm{O}$ nome verdadeiro foi omitido para a preservação da identidade da pessoa indicada na fala do G1.
} 
“(...) eu me sinto um pouco solta, sem muito falar em PDI, contanto que eu esqueci quase tudo do PDI” (risos).

“(...) que até por isso que eu fui deixando de lado porque não tem ninguém do quadro. Tenho lá os prestadores que estão altamente desestimulados e pensando já que vão sair, então isso aí não está sendo aplicado”.

(Entrevistado G1)

"Ocorre mais pela parte financeira e pela parte de desenvolvimento pessoal..."

(Entrevistado G2)

(...) é.... a gente procura seguir estas metas, entretanto nós temos limitação externa, tanto do Ministério do Planejamento, quanto do Ministério da Educação, interferem muito nessa busca, nessa possibilidade da Instituição atingir estas metas que foram pré-estabelecidas".

(Entrevistado G4)

Conforme expõe Estevão (1998) existe uma relação entre a gestão estratégica e os outros fatores que compõem a organização, como o planejamento estratégico, as necessidades de recursos, a estrutura e processos organizacionais e o controle estratégico, e a gestão estratégica é o eixo da roda que proporciona essa interação, conforme mostra a Figura 3, constante do Capítulo 2, subitem 2.3, porém percebe-se que nas gerências da SRH há falta de interação entre os diversos fatores que compõem os ambientes internos e externos da universidade em suas gestões, o que pode provocar a criação de obstáculos para suas atuações.

Cada um dos fatores que compõe o ambiente exerce uma influência sobre a gestão estratégica, os recursos são fundamentais para apoiar as decisões do gestor, o planejamento estratégico é essencial para a definição da missão e dos objetivos, e o fator organizacional e o controle estratégico interfere no estilo da decisão e na avaliação (ESTEVÃO, 1998). 


\begin{tabular}{|c|c|}
\hline Entrevistados & $\begin{array}{l}\text { Categoria 2: Percepção quanto à parceria da SRH com a UnB no } \\
\text { planejamento estratégico constante do PDI. }\end{array}$ \\
\hline G1 & $\begin{array}{l}\text { "Sim, em algum ponto. As metas do PDI...não assim no geral, o todo. Realmente } \\
\text { começou mais apurada foi em } 2008 \text { nas reuniões para o cumprimento, para ver o } \\
\text { relacionamento de chefia - servidor, os cursos oferecidos e hoje em dia em } 2009 \text {, eu me } \\
\text { sinto um pouco solta, sem muito falar em PDI, contanto que eu esqueci quase tudo do } \\
\text { PDI" (risos). } \\
\text { "Esta gestão SRH e o plano de desenvolvimento da UnB.... na minha sala quase não tem } \\
\text { como estar aplicando no dia-a-dia, eu acho assim ... que até por isso que eu fui deixando } \\
\text { de lado porque não tem ninguém do quadro. Tenho lá os prestadores que estão altamente } \\
\text { desestimulados e pensando já que vão sair, então isso aí não está sendo aplicado". }\end{array}$ \\
\hline G2 & $\begin{array}{l}\text { "Sim, porque a Universidade está interligada com toda a situação da Universidade, } \\
\text { inclusive como a nova contratação de professores, como meta pra gerência de cursos e a } \\
\text { nova estratégia é a nova cara da Universidade". } \\
\text { "Ocorre mais pela parte financeira e pela parte de desenvolvimento pessoal que trata de } \\
\text { cursos, especialização e captação de recursos para melhoria do servidor no trabalho". }\end{array}$ \\
\hline G3 & $\begin{array}{l}\text { "Sim. Porque constantemente estamos dando ciência das ações que desenvolvemos aqui } \\
\text { e ele nos dá o feedback". } \\
\text { "As decisões tomadas (...) são necessariamente repassadas para Gestão da SRH e a partir } \\
\text { da decisão tomada pela SRH a gente dá segmento ao PDI". }\end{array}$ \\
\hline G4 & $\begin{array}{l}\text { "O que me parece aqui....por exemplo.... SRH...talvez assim...me parece ser uma coisa } \\
\text { ampla no âmbito da SRH, uma coisa assim, uma resposta mais direta seria do Secretário } \\
\text { de Recursos Humanos mesmo, que tem um conhecimento do todo, mas quanto a parte da } \\
\text { minha área específica, (...) é.... a gente procura seguir estas metas, entretanto nós temos } \\
\text { limitação externa, tanto do Ministério do Planejamento, quanto do Ministério da } \\
\text { Educação, interferem muito nessa busca, nessa possibilidade da Instituição atingir estas } \\
\text { metas que foram pré-estabelecidas". } \\
\text { "Bom... eu acho que... ou deveria ser, a SRH deveria estar ligada, deveria estar focada } \\
\text { em atender ao Plano de Desenvolvimento Institucional da UnB porque esse plano é um } \\
\text { plano que, ele tem que ser seguido. É um planejamento que a Instituição faz por um } \\
\text { período X e que todas as unidades da Instituição devem estar focadas em atender aquele } \\
\text { plano, prá que todas as metas sejam todas atingidas". }\end{array}$ \\
\hline G5 & $\begin{array}{l}\text { "Sim. Ela participa efetivamente assim como os outros centros de custos também } \\
\text { participam". } \\
\text { "Olha, a parceria ocorre no momento em que a SRH fornece, alimenta com as } \\
\text { informações necessárias para a composição do plano, do PDI, então, ela participa desta } \\
\text { forma". }\end{array}$ \\
\hline G6 & $\begin{array}{l}\text { "Considero em parte, não atende a todas as metas estabelecidas. Porque as vezes nós não } \\
\text { conseguimos cumprir todas as metas que está lá no papel, a gente tem que procurar e } \\
\text { assumindo as metas na medida em que elas vão surgindo. } \\
\text { "(...) acontece no atendimento dos pedidos dos institutos, (...)". }\end{array}$ \\
\hline
\end{tabular}

Quadro 3: Categoria Percepção quanto a parceria da SRH e planejamento estratégico no PDI da UnB Fonte: Pesquisa de campo, 2009.

Na categoria 3, percebe-se que os gerentes têm pouca visão geral da Instituição. Ainda não conseguem visualizar que a sua gerência é uma parte da SRH na aplicabilidade das bases do PDI. As respostas deixam evidente uma visão individualista, conforme se verifica nos relatos abaixo: 
“(...) Nós trabalhamos as nossas metas. Se não tivermos o apoio da Administração Superior as metas definidas pela Gerência podem não ser alcançadas”.

(Entrevistado G3)

“(...)A minha gerência, ela participa com suas necessidades, seus planejamentos...”

(Entrevistado G5) 


\begin{tabular}{|c|c|}
\hline Entrevistados & $\begin{array}{l}\text { Categoria 3: Participação e importância da SRH no planejamento estratégico } \\
\text { da UnB }\end{array}$ \\
\hline G1 & $\begin{array}{l}\text { "Eu acho o seguinte: que nós deveríamos ser mais cobrados e sempre estar tendo as } \\
\text { reuniões pra que houvesse verdadeiramente a aplicação do PDI. } \\
\text { "Sim. A participação, principalmente no que se refere (...). Nós pensávamos em montar } \\
\text { um plano.... (...) porém este plano também está totalmente parado. Eu acho que o que está } \\
\text { faltando é mais uma integração e mais uma cobrança mesmo a gerência geral para que a } \\
\text { gente esteja atento ao PDI. } \\
\text { "É...realmente eu não vou responder esta, porque como eu tenho falado, que eu esqueci } \\
\text { um pouco do plano". }\end{array}$ \\
\hline G2 & $\begin{array}{l}\text { "A Universidade, ela procura melhorar a vida do servidor, tanto dentro como fora da } \\
\text { Instituição, no âmbito da Universidade no geral, tanto como participação interna e externa } \\
\text { e a melhoria do servidor no âmbito geral". } \\
\text { "Sim. As atividades desenvolvidas na gerência de Recursos Humanos, ela tem um papel } \\
\text { importante na comunidade (...) e, no modo geral, (...)". } \\
\text { "A importância do PDI da SRH, ela é mais voltada para uma parte do planejamento } \\
\text { estratégico das atividades a serem alcançadas pela Instituição. Entendo também que o PDI } \\
\text { é uma forma de manter a organizaça e o planejamento que possa ser voltado para } \\
\text { gerenciar as atividades da Universidade, bem como a melhoria dos serviços da SRH". }\end{array}$ \\
\hline G3 & $\begin{array}{l}\text { "Não sei informar". } \\
\text { "Sim". O desenvolvimento e implementação do (...) tem como um dos objetivos o } \\
\text { desenvolvimento e aperfeiçoamento profissional dos servidores na Instituiçãa". } \\
\text { "Acho que muito importante, pois há diretrizes definidas pela Administração Superior. } \\
\text { Nós trabalhamos as nossas metas. Se não tivermos o apoio da Administraçâo Superior as } \\
\text { metas definidas pela Gerência podem não ser alcançadas". }\end{array}$ \\
\hline G4 & $\begin{array}{l}\text { "A SRH como unidade de apoio à Reitoria, à Administração Superior, ela deve dar } \\
\text { suporte à Administração Superior para que a Administração Superior possa atingir estas } \\
\text { metas, a UnB possa atingir estas metas, então a SRH, ela é uma unidade de apoio, não só à } \\
\text { Reitoria, como às demais unidades da Instituição". } \\
\text { "Sim e de maneira bastante direta, porque assim uma gerência que....ela pode ser } \\
\text { considerada porta de entrada dos servidores, tanto técnicos como docentes na Instituição } \\
\text { (...)". } \\
\text { "A importância da SRH é que ela como unidade da Instituição e como o PDI, ele } \\
\text { estabelece as metas a serem alcançadas pela Instituição, então, algumas metas serão } \\
\text { passadas para SRH. A SRH vai ter que alcançar estas metas e ela, alcançando estas metas, } \\
\text { consequientemente, a própria Instituição alcançará as metas porque ela faz parte, é como o } \\
\text { corpo humano, ela é uma parte do corpo humano. Se o corpo humano tem que chegar } \\
\text { àquele local, todas as partes do corpo têm que estar cumprindo a sua função para que se } \\
\text { consiga alcançar o objetivo final da Instituição". }\end{array}$ \\
\hline G5 & $\begin{array}{l}\text { "Existe uma reunião entre o nosso Secretário com todos os gerentes da SRH, onde todos } \\
\text { colocam suas necessidades, colocam seus pontos de vistas, de modo a traçar um } \\
\text { planejamento". } \\
\text { "Sim. A minha gerência, ela participa com suas necessidades, seus planejamentos, o que é } \\
\text { feito atualmente e sempre procurando melhorias, evidentemente sempre se adequando ao } \\
\text { plano, então desta forma a gente participa, alimentando com informações do nosso setor } \\
\text { para SRH e esta, conseqüentemente para o PDI". } \\
\text { "É importante porque o PDI, ele sendo implantado, vai depender que a SRH também } \\
\text { contribua com a sua parte, então ela tem que fazer as coisas de acordo como estão sendo } \\
\text { planejadas". }\end{array}$ \\
\hline G6 & $\begin{array}{l}\text { "A elaboração do processo envolveu a equipe técnica composta por gerentes da SRH”. } \\
\text { "Identifico sim". (...) } \\
\text { "A SRH é responsável pela criação, atualização e reformulação dos seus programas". }\end{array}$ \\
\hline
\end{tabular}

Quadro 4: Categoria Participação e importância da SRH no planejamento estratégico da UnB Fonte: Pesquisa de campo, 2009. 
Depois de estabelecidos os objetivos e as estratégias, o papel da área de Recursos Humanos é fundamental para a implementação do que foi planejado, por isso as políticas de RH devem estar de acordo com as estratégias da organização, pois a organização é um conjunto de pessoas que trabalham para satisfazer as suas necessidades, faz-se necessário que o interesse das pessoas esteja orientado para atender aos objetivos organizacionais (ANSOFF 1977 apud ALMEIDA 1993).

Com o objetivo de alinhar a função de recursos ao posicionamento da organização, algumas ações são importantes, como: inserção dos recursos humanos na gestão estratégica; criação de ambiente propício a mudanças e aprendizagem organizacional; gestão da cultura organizacional e constituição e fortalecimento do trabalho em equipe (SANTOS; CARPINETTI; GONÇALVES, 1997 apud ESTHER; PAÇO-CUNHA; MACHADO, 2006).

Dessa forma, nota-se que há possibilidade das gerências de RH assumirem uma postura mais estratégica ao desenvolverem suas atividades e contribuírem para o alcance dos objetivos almejados pela comunidade universitária, conforme os documentos elaborados pela Instituição.

\section{3 - Diferenças verificadas quanto ao Plano de Desenvolvimento Institucional da UnB e as ações do planejamento das gerências de Recursos Humanos}

Em resposta a esta questão foram consideradas as categoria 4 - Relação entre as atividades executadas na área de RH e o PDI da UnB e 5 - Relação de equipe de trabalho e o planejamento estratégico da UnB.

$\mathrm{Na}$ categoria 4 é interessante verificar que nenhum dos entrevistados citou uma atividade sequer que estivesse de acordo com o PDI da UnB, Apêndice B - Quadro 2, conforme se verifica, por exemplo, por meio do relato a seguir.

\footnotetext{
"Sim, existe uma relação sim, entre as atividades executadas no meu setor para com a SRH e, esta evidentemente, para com o planejamento".
} 


\begin{tabular}{|c|c|}
\hline Entrevistados & $\begin{array}{l}\text { Categoria } 4 \text { - Relação entre as atividades executadas na área de RH e o PDI } \\
\text { da UnB }\end{array}$ \\
\hline G1 & $\begin{array}{l}\text { "É, eu não sei se estão totalmente ligadas ao PDI, porque como eu falei no começo. Foi } \\
\text { no começo de } 2008 \text { que a gente teve uma reunião e eu nunca mais me liguei no PDI". }\end{array}$ \\
\hline G2 & $\begin{array}{l}\text { "Tem, mesmo porque a Gerência de Recursos Humanos tem as metas a serem } \\
\text { alcançadas, (...) e outros programas que estão previstos no próprio plano, no PDI, para } \\
\text { melhor facilitar as atividades no âmbito da Universidade. }\end{array}$ \\
\hline G3 & $\begin{array}{l}\text { "Sim. São planejadas atividades baseadas nas metas do PDI para alcance das mesmas, } \\
\text { bem como outras atividades que propicia a melhoria do trabalho e da capacitação das } \\
\text { pessoas do setor". }\end{array}$ \\
\hline G4 & $\begin{array}{l}\text { "Eu acho que sim, pelos motivos já explicitados na questão anterior. Por exemplo, agora } \\
\text { com o advento do REUNI, reorganização das universidades, que foi pactuado entre as } \\
\text { Instituições Federais de ensino e o Ministério da Educação, nós estamos recebendo } \\
\text { vários servidores que foram concursados para serem distribuídos em várias unidades, } \\
\text { vários cursos que estão sendo abertos e isso, de alguma maneira bem significativa, vai } \\
\text { contribuir para o alcance dos objetivos da Instituição". }\end{array}$ \\
\hline G5 & $\begin{array}{l}\text { "Sim, existe uma relação sim, entre as atividades executadas no meu setor para com a } \\
\text { SRH e, esta evidentemente, para com o planejamento". }\end{array}$ \\
\hline G6 & $\begin{array}{l}\text { "Sim. No desenvolvimento de atividades (...), visando o atendimento das reais demandas } \\
\text { de trabalho às necessidades da UnB e da sociedade". }\end{array}$ \\
\hline
\end{tabular}

Quadro 5: Categoria Relação entre as atividades executadas na área de RH e o PDI da UnB Fonte: Pesquisa de campo, 2009.

Quanto à categoria 5 verifica-se que conforme consta do Plano de Desenvolvimento Institucional - Apêndice B - Quadro 2, desta monografia, uma das metas estabelecidas, é a implementação de programa de capacitação de servidores. Portanto, percebe-se com as respostas de todos os gerentes a busca pela qualidade na execução do trabalho, ainda de uma forma "individualizada" por setor.

Esse fato demonstra mais uma vez o pouco conhecimento, por parte dos gerentes, referente aos documentos que orientam a atuação da SRH e, principalmente, uma relação concreta e ativa com a equipe de trabalho dentro das diretrizes do planejamento estratégico da universidade. 


\begin{tabular}{|c|c|}
\hline Entrevistados & $\begin{array}{l}\text { Categoria 5: Relação de equipe de trabalho e o planejamento estratégico da } \\
\text { UnB }\end{array}$ \\
\hline G1 & $\begin{array}{l}\text { "Olha, mais uma vez eu vou dizer que se não estou lembrando, então como é que eu vou } \\
\text { fazer uma revelação das atividades desenvolvidas com o PDI. Eu só sei o seguinte: que as } \\
\text { atividades executadas (...), elas são assim de uma grande relevância par a UnB (...)" } \\
\text { "Os esforços ali... eu te garanto uma coisa, tem sido assim grandes os esforços porque } \\
\text { temos três pessoas trabalhando (...). Muitas vezes até uma reunião para direcionar uma } \\
\text { atividade fica difícil para largarem a rotina (...)". }\end{array}$ \\
\hline G2 & $\begin{array}{l}\text { "Com certeza. Inclusive existem reuniões semanais e até, às vezes, antes deste período, } \\
\text { para mostrar a identidade da nova Universidade, tanto pelo REUNI e pela necessidade de } \\
\text { mostrar o que a Universidade e o papel que ela representa dentro da nossa gerência de } \\
\text { Recursos Humanos". } \\
\text { "Essa é uma meta mais importante porque eu lembro sempre que todas as pessoas que vêm } \\
\text { trabalhar na Gerência (...). Então, esta Secretaria tem como manter sempre atualizado e as } \\
\text { informações prestadas junto a sociedade". }\end{array}$ \\
\hline G3 & $\begin{array}{l}\text { "Penso que sim. A conscientização da equipe sobre a importância das atividades é por meio } \\
\text { de reuniões periódicas, nós discutimos os resultados alcançados, nós procuramos buscar } \\
\text { meios para resolver as dificuldades que encontramos juntos". } \\
\text { "Nós conversamos e definimos prazos". }\end{array}$ \\
\hline G4 & $\begin{array}{l}\text { "Sim. Periodicamente faz reuniões porque no meu setor são várias atividades que são } \\
\text { desempenhadas, (...). } \\
\text { "Justamente mostrando a elas a importância do trabalho de cada um. Que todos são } \\
\text { importantes, todos da equipe são importantes no desenvolvimento das atividades, então, } \\
\text { todos os servidores tem consciência e, isso eu procuro conversar com cada um, para que } \\
\text { eles tenham consciência do que eles estão fazendo. Por exemplo, é um trabalho mecânico } \\
\text { ali que o servidor está desempenhando, sem saber. Você pergunta - Ah! Você está fazendo } \\
\text { isso prá quê? - Ah! Não sei! Ele tá fazendo aquilo mecanicamente. Não! No meu setor eu } \\
\text { procuro dizer, toda vez que eu passo um trabalho eu falo: Oh, isso aqui que eu tô lhe } \\
\text { passando...eu conto a história, eu dou o porque que ele vai desempenhar esta atividade, } \\
\text { então ele tem consciência para desempenhar aquela atividade, o quê que, ao final do } \\
\text { desempenho dessa atividade, qual o fruto que será colhido pela Instituição". }\end{array}$ \\
\hline G5 & $\begin{array}{l}\text { "Sim. Eles são conscientizados das suas tarefas a serem realizadas, de modo a atender aos } \\
\text { anseios da UnB, que evidentemente estão dentro de um planejamento estratégico". } \\
\text { "Atendendo bem ao servidor, de um modo geral, aos centros de custos, (...)". }\end{array}$ \\
\hline G6 & $\begin{array}{l}\text { "Sim, porque não adianta só os Gerentes saberem das metas. Eu acho que todos têm que } \\
\text { estar envolvidos". } \\
\text { "Explicando a importância do nosso trabalho e objetivos". }\end{array}$ \\
\hline
\end{tabular}

Quadro 6: Categoria Relação de equipe de trabalho e o planejamento estratégico da UnB Fonte: Pesquisa de campo, 2009.

Para Ansoff (1977 apud ALMEIDA 1993) "faz-se necessário que o interesse das pessoas esteja orientado para atender aos objetivos organizacionais", diante de tal afirmação, verifica-se, por meio dos relatos nas categorias 4 e 5 dos gerentes da SRH entrevistados, que a maioria das equipes não caminham de acordo com Plano de Desenvolvimento Institucional da UnB, uma vez que buscam implementar atividades a partir de uma visão operacional individualizada, não considerando a Instituição como um todo. 


\section{4 - Similaridades constatadas do Plano de Desenvolvimento Institucional e as ações do planejamento das gerências de Recursos Humanos.}

A categoria 6 - Participação da Gerência no planejamento da UnB - identifica elementos que respondem ao último objetivo específico deste estudo, que é apontar similaridades constatadas do Plano de Desenvolvimento Institucional da UnB e as ações e as ações do planejamento das gerências de Recursos Humanos.

Os relatos dos gerentes abaixo deixam evidente que existem ações aleatórias de planejamento estratégico em suas respectivas unidades, porém não foi possível analisar se tais ações estão de acordo com Plano de Desenvolvimento Institucional, conforme Apêndice A Quadro 2, tendo em vista que eles não conseguiram citar de forma objetiva quais são as ações para o alcance destas metas estabelecidas do PDI da UnB, como também não apresentaram nenhum documento de formalização das ações a serem desenvolvidas em suas gerências.

\begin{tabular}{|c|c|}
\hline Entrevistados & Categoria 6 - Participação da Gerência no planejamento da UnB \\
\hline G1 & $\begin{array}{l}\text { "Se eu tenho falado, que eu esqueci um pouco do plano, do planejamento estratégico, é... o } \\
\text { que eu posso falar é que a Gerência (...) tem procurado cumprir com suas obrigações, } \\
\text { orientando os servidores na hora que ele vem pedir. (...) Nós tiramos todas as dúvidas, não } \\
\text { só para aqueles que se aproximam lá da nossa sala (...)". }\end{array}$ \\
\hline G2 & $\begin{array}{l}\text { "Como havia dito antes, a participação da Gerência de Recursos Humanos, (...), eu acho } \\
\text { que é de importância tanto para Universidade como para Gerência de Recursos Humanos, } \\
\text { para desafogar as atividades e diminuir o fluxo de documento existente (...)". }\end{array}$ \\
\hline G3 & $\begin{array}{l}\text { "No ano de } 2008 \text { participamos de uma reunião, convidados pela Gestão da SRH para } \\
\text { trabalharmos o planejamento estratégico da SRH. Vejo que esta é uma participação (...) } \\
\text { junto ao planejamento estratégico da SRH e, por consequência, da UnB". }\end{array}$ \\
\hline G4 & $\begin{array}{l}\text { "Esta participação da minha Gerência no planejamento estratégico da UnB ela se dá pelo } \\
\text { desenvolvimento das próprias atividades das gerências, (...). A gente através do estudo que } \\
\text { até foi feito, a gente poderia distribuir melhor esta mão de obra pela Instituição e, } \\
\text { principalmente, estas são as atividades principais: (...)" }\end{array}$ \\
\hline G5 & $\begin{array}{l}\text { "(...) Nossos colaboradores trabalham com afinco, de modo a atender as metas que foram } \\
\text { traçadas, fazendo com que os ambientes do trabalho sejam cada vez melhores, levando a } \\
\text { excelência como a nossa meta, }(\ldots) \text {.. }\end{array}$ \\
\hline G6 & $\begin{array}{l}\text { "A participação da gerência é através da capacitação de curta e média na identificação das } \\
\text { necessidades de capacitação entre as metas estabelecidas". }\end{array}$ \\
\hline
\end{tabular}

Quadro 7: Categoria Participação da Gerência no planejamento da UnB

Fonte: Pesquisa de campo, 2009. 
Para Delgado Filho (2004) o planejamento estratégico é utilizado como instrumento de integração, a participação no pensamento estratégico da organização é mais importante do que o produto final, portanto, qualquer plano bem alinhado é melhor do que um bom plano sem o devido envolvimento. Observa-se, com isto, que os gerentes entrevistados ainda precisam aprimorar ou mesmo desenvolver uma visão estratégica no tocante à importância de ações de planejamento em suas respectivas áreas. 


\section{CONSIDERAÇÕES FINAIS}

Este estudo buscou analisar o alinhamento entre o planejamento estratégico da Universidade de Brasília e as atividades de planejamento desenvolvidas pelas gerências que compõem a Secretaria de Recursos Humanos - SRH. Contudo, percebeu-se que há pouca integração das gerências que formam a SRH da UnB e insuficiente conhecimento, por parte dos gerentes, quanto aos documentos que orientam os gestores sobre como implementar e aplicar o Plano de Desenvolvimento Institucional da UnB, sendo esses fatores que evidenciam, como conclusão deste estudo, um conhecimento insuficiente de um alinhamento estratégico das gerências com o planejamento estratégico da Universidade.

Para que se possa construir uma gerência alinhada ao planejamento estratégico da Universidade é necessária uma nova perspectiva de gestão, pois para Lipec (2001 apud ESTHER; PAÇO-CUNHA; MACHADO, 2006) os gerentes da área de Recursos Humanos devem contribuir para os resultados e desenvolvimento da Instituição, e por meio de uma visão holística, conseguir alinhar estrategicamente suas atividades ao planejamento estratégico da organização.

De acordo com as informações levantadas neste estudo alguns fatores podem ser apontados como sugestões para melhorar o alinhamento em questão, tais como:

- Reuniões periódicas entre o Secretário Geral da SRH e seus gerentes de sub-áreas de RH para estudo do Manual de Planejamento e meios de aplicá-lo;

- Reuniões periódicas das respectivas gerências com suas equipes de trabalho;

- Feedback do Secretário Geral da SRH às gerências quanto às propostas elaboradas para o PDI enviadas à Secretaria de Planejamento da UnB.

- Utilização do Manual de Planejamento como instrumento que norteia as metas e ações de cada gerência da SRH para a Instituição. 


\section{REFERÊNCIAS}

ALMEIDA, Martinho Isnard Ribeiro de; et al. Por que administrar estrategicamente recursos humanos? Revista de administração de empresas, p. 12-24. São Paulo, 1993.

BASES DO PLANEJAMENTO ESTRATÉGICO E TÁTICO. Fundação Universidade de Brasília. Brasília, 2007. p. 9-13; 30. Disponível em www.unb.br/spl

CHIAVENATO, Idalberto. Introdução à teoria geral da administração. 4. ed. São Paulo: Makron Books, 1993.

DELGADO FILHO, Adauto Bezerra; BACIC, Miguel Juan. Planejamento Estratégico em Universidades Públicas: Diferenças e Recomendações. Florianópolis: NUPEAU/UFSC - IV Colóquio Internacional sobre Gestão Universitária na América do Sul, 2004.

ESTEVÃO, Carlos. Gestão estratégica nas escolas. Cadernos de Organização e Gestão Curricular, Instituto de Inovação Educacional, 1998. Lisboa: IIE

ÉSTHER, Ângelo Brigato; PAÇO-CUNHA, Elcemir; MACHADO, Márcia Cristina da Silva. Alinhamento estratégico da gestão de recursos humanos: o caso de uma grande empresa de embalagens. In: IV SIMPÓSIO DE GESTÃO E ESTRATÉGIA EM NEGÓCIOS, Setembro de 2006, Seropédica - Rio de Janeiro.

FARIAS, Josivania Silva; MENEZES, Marcello. RH Estratégico: Um olhar do Corpo Funcional de uma distribuidora de produtos hospitalares. In: VI SIMPÓSIO DE GESTÃO E ESTRATÉGIA EM NEGÓCIOS, setembro de 2008, Seropédica - Rio de Janeiro.

FARIAS, Josivania Silva; SENNA, Eliane Bruna Oliveira dos Santos. Alinhamento da Gestão de Pessoas à Estratégia Organizacional. In: V ENCONTRO DE ESTUDOS SOBRE EMPREENDEDORISMO E GESTÃO DE PEQUENAS EMPRESAS, março de 2008, São Paulo - São Paulo.

FRANCO, Maria Laura P. B. Análise de Conteúdo: Série Pesquisa. v. 6, 2 ed. Brasília, 2007. p. 51-52.

LEMOS, Antônio Carlos Freitas Vale et al. O planejamento estratégico como ferramenta competitiva. In: VII SEMEAD, agosto de 2005, São Paulo - São Paulo.

MANUAL DE PLANEJAMENTO 2006-2010. Fundação Universidade de Brasília. Brasília, 2007. p. 6-15. Disponível em www.unb.br/spl

MARCELINO, Gileno Fernandes. Planejamento estratégico no setor público: uma experiência no Palácio do Planalto. Revista do Serviço Público n. 4, 2002.

p. 29-36.

(Org). Gestão estratégica de universidade. Universidade de Brasília. Brasília, 2003. 
MELLEIRO, Marta Maria; TRONCHIN, Daisy Maria Rizatto; CIAMPONE, Maria Helena Trench. O planejamento estratégico situacional no ensino do gerenciamento em enfermagem. Acta Paulista de Enfermagem. 2005, v. 18, no. 2, p. 165-171.

MORAES, Paulo Henrique de Almeida. Manutenção Produtiva Total: estudo de caso em uma empresa automobilística. 2004. 90 f. Dissertação (Mestrado em Gestão e Desenvolvimento Regional) - Departamento de Economia, Contabilidade e Administração, Universidade de Taubaté, Taubaté.

OLIVEIRA, Djalma de Pinho Rebouças de. Estratégia empresarial: uma abordagem empreendedora. 2 ed. São Paulo: Atlas, 1991.

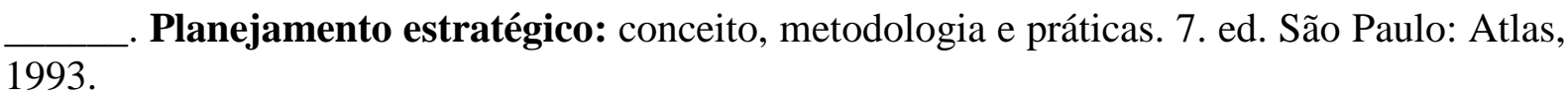

RICHARDSON, Roberto Jarry et al. Pesquisa social: métodos e técnicas. 2. ed. São Paulo: Atlas, 1989. p. 173-194

Pesquisa social: métodos e técnicas. São Paulo: Atlas, 1999.

ROCHA, Welinton. Contribuição ao Estudo de um Modelo Conceitual de Sistema de Informação de Gestão Estratégica. 1999. 158f. Tese (Doutorado em Ciências Contábeis) Faculdade de Economia, Administração e Contabilidade da Universidade de São Paulo, São Paulo.

SENNA, Eliane Bruna Oliveira dos Santos. O alinhamento da área de gestão de pessoas à estratégia organizacional: o caso de um banco brasileiro. Monografia de Pós-Graduação Lato Sensu em Gestão de Pessoas. Universidade de Brasília. Brasília, 2007.

UNIVERSIDADE DE BRASÍLIA. Ato da Reitoria n. 1011, de 30/4/1997. Estrutura básica da Secretaria de Recursos Humanos. Brasília: 1997.

VERGARA, Sylvia Constant. Projetos e relatório de pesquisa em administração. 8. ed. São Paulo: Atlas, 2007.

WRIGHT, Peter; KROLL, Mark J.; PARNELL, John. Administração Estratégica: conceitos. São Paulo: Atlas, 2000. 


\section{APÊNDICE A - Roteiro de Entrevista}

Prezado (a) Senhor (a): esta entrevista tem por objetivo coletar informações sobre a percepção dos gestores de Recursos Humanos quanto ao alinhamento entre o planejamento estratégico da Universidade de Brasília e as atividades de planejamento de suas áreas específicas. Esperando contar com sua valiosa colaboração, asseguramos que:

- As informações prestadas são sigilosas e utilizadas apenas para fins de pesquisa;

$>$ Elas serão analisadas em conjunto com as informações fornecidas por outras pessoas; não sendo possível identificar o entrevistado separadamente.

> Mediante autorização dos entrevistados as entrevistas serão gravadas;

$>$ Em caso de dúvidas quanto à redação das perguntas, poderão ser solicitados esclarecimentos à entrevistadora.

Sexo- ( ) M ( ) F

Idade - ( ) de 24 a 28 anos ( ) de 29 a 35 anos ( ) de 36 a 42 anos ( ) acima de 43 anos Cargo de origem:

Tempo de UnB:

Tempo na função:

1. Antes de assumir a função atual, o (a) senhor (a) fez algum tipo de curso que o (a) preparasse para assumi-lo? Quais?

2. O (A) senhor (a) já assumiu ou substituiu outras funções de gerências anteriormente? Quais?

3. O Plano de Desenvolvimento Institucional - PDI é o documento que contém o plano estratégico da universidade de Brasília - UnB para 2006 a 2010. O (A) senhor (a) como gerente, conhece as metas estabelecidas para a Secretaria de Recursos Humanos - SRH neste documento? Quais?

4. O (A) senhor (a) considera a gestão da SRH como um parceiro no planejamento das metas estabelecidas para o Plano de Desenvolvimento Institucional da UnB? Por quê? 
5. Em sua opinião de que forma ocorre a parceria "Gestão SRH e Plano de Desenvolvimento Institucional da UnB"?

6. Como ocorre a participação da SRH no processo de planejamento estratégico da UnB?

7. O (A) senhor (a) identifica a participação e contribuição das atividades executadas na sua gerência nos objetivos institucionais da UnB?

8. Na sua opinião, existe uma relação entre as atividades executadas na sua gerência e os objetivos do Plano de Desenvolvimento Institucional da UnB?

9. O (A) senhor conscientiza sua equipe de trabalho sobre a importância das atividades executadas na gerência para o planejamento estratégico da UnB?

10. De que forma o (a) senhor (a) faz esforços para que a sua equipe de trabalho se conscientize e trabalhe com foco nos objetivos da SRH?

11. Qual a importância do plano de desenvolvimento institucional da UnB no planejamento das metas da SRH?

12. Fale um pouco sobre a participação da sua gerência no planejamento estratégico da UnB. 


\section{APÊNDICE B - Plano de Desenvolvimento Institucional por Unidade - 2007 a 2010} Quadros 1 e 2

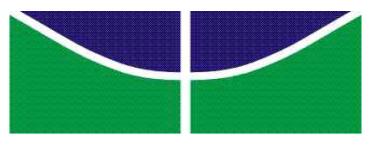

\section{Plano de Desenvolvimento Institucional}

Diagnóstico Institucional - Quadro 1

A - Objetivo Geral da Unidade para 2007-2010: $\quad$ SRH Secretaria de Recursos Humanos Ser instituição pública de referência nacional na gestão de recursos humanos motivados, qualificados, comprometidos com a qualidade das atividades acadêmicas e da gestão transparente e ética.

B - Ambiente Externo

Ameaças

Descrição:

Descrição: Restrições orçamentárias

Descrição: Apos entadorias sem perspectivas de reposição

Descrição: Aumento da concorrência técnico-especializada

Descrição: Inadequação da política de RH do Governo para as IFES

Oportunidades

Descrição:

Descrição: Imagem Positiva da Universidade de Brasília

Descrição: Possibilidades de realização de parcerias

Descrição: Existência de recursos disponíveis para captação

Descrição: Discussão nacional sobre o papel estratégico de $\mathrm{RH}$ no desenvolvimento das IFES

ente Interno

Pontos Fortes

Descrição:

Descrição: Localização geográfica

Descrição: Liderança científica e na geração de conhecimentos

Descrição: Recursos Humanos qualificados

Descrição: PDI operacionalizado

Pontos Fracos

Descrição:

Descrição: Localização geográfica

Descrição: Liderança científica e na geração de conhecimentos

Descrição: Recursos Humanos qualificados

Descrição: PDI operacionalizado

D - Sugestões

Aperfeiçoamento do sistema de planejamento da UnB

Descrição: "Sintetização e organização das informações captadas, de modo a obter um banco de dados unificado e, assim, diminuir a

Prioridade institu cionais da UnB para o período

Descrição: Política de valorização dos recursos humanos da Instituição

Descrição: Política de valorização dos recursos humanos da Instituição

Descrição: Exploração das oportunidades de prestação de serviços internos e extemos

E - Avaliação dos Planejamento Institucional exercicio anterior

I. Quanto aos resultados alcançados

1 -

2-O sistema

$3-0$

II. Quanto à participação da uniade no planejamento

1 -

2-

3-

III. Quanto aos intrumentos de planejamento utilizado

1 -

2-

$3-$

$5-$

IV. Quanto à estruturação do planejamento

1 -

3-Acesso

4-Utilização$$
\text { Utilização }
$$ 

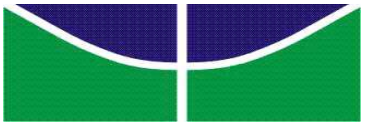

\section{Plano de Desenvolvimento Instirucional}

\section{Plano Plurianual de Atividades - Quadro 2}

Unidade: Secretaria de Recursos Humanos

\section{Área Diretriz Prioridade, № do Objetivo Metas Globais}

5 Desenvolvimento Comunitário

O4D5

91 Promover ações de Segurança no Trabalho até 2010

1 Inspeção de $100 \%$ dos ambientes e atividades com risco de acidentes de trabalho a cada 2 anos, até 2010

2 Controle de $100 \%$ das concessões de Insalubridade e Periculosidade aos servidores envolvidos até 2010

3 Realização anual de campanhas educativas para prevenção de acidentes até 2010

4 Criação e manutenção de uma Brigada de Incên dio até 2010

192 Implantar, manter e ampliar Programas de Desenvolvimento de Pessoas até 2010

1 Manutenção e ampliação do Projeto "VIV A BEM UnB" até 2010

2 Implantação e manutenção do Programa de Preparação para a A posentadoria até 2010

6 Recursos Humanos

O5D1

53 Implementar Programa de Avaliação dos Servidores, conforme as diretrizes do Plano de Carreira

1 Aprovação, implantação e acompanhamento do Programa de Avaliação dos Servidores até Aprovação, implantação e acompanhamento do Programa de Avaliação dos Servidores até

2 Quantificação do alcance de $90 \%$ em excelência no desempenho dos senidores da UnB até 2010

3 Implantação do Projeto de Premiação de Excelência no Desempenho Funcional até 2010

74 Manter e ampliaro Programa de Formação Gerencial

1 Realização de 8 turmas presenciais do Curso de Formação Gerencial até 2010

2 Implantação e manutenção do Programa de Formação Gerencial à Distância até 2010

$8 \quad 7$ Promover Cursos de Formação Didática para Docentes

1 Realização de 7 turmas de Formação Didática para os Docentes até 2010

145 Implantar Banco Estratégico de Talentos

1 Criação do Sistema de Banco Estratégico de Talentos até 2008

O5D3

36 Manter e ampliaro Quadro de Docentes Doutores com Dedicação Exclusiva

1 Contratação de Docentes Doutores em regime de Dedicação Exclusiva que at enda a 60\% das Unidades até 2010

2 Manutenção de $10 \%$ ao ano do Quadro de Docentes em contratação temporária (Substitutos) até 2010

O5D4

68 Implementar o Programa de Capacitação dos Servidores, de acordo com as diretrizes do Plano de Carreira

1 Aprovação, implantação e acompanhamento do Programa de Capacitação dos Servidores até 2010

2 Capacitação de $100 \%$ da Força de Trabalho da UnB até 2010 , de acordo com as necessidades identificadas

3 Realização de 2 palestras mensais das Quartas Gerenciais até 2010

4 Realização de Eventos Comemorativos e de Integração até 2010

O5D5

5 Capacitação/qualificação da força de trabalho da SRH até 2010

19 Gerir com efetividade o Quadro de Pessoal da FUB

1 Manutenção da Folha de Pagamento de Pessoal A tivo até 2010

2 Manutenção da Folha de Pagamento de Aposentados até 2010

3 Manutenção da Folha de Pagamento de Pensionistas (Pensão Federal) até 2010

4 Manutenção da Folha de Pagamento de Benefícios: Auxílio Pré-Escolar até 2010

5 Manutenção da Folha de Pagamento de Benefícios: Auxílio Transporte até 2010

6 Manutenção da Folha de Pagamento de Benefícios: Auxílio Alimentação até 2010

7 Manutenção da Folha de Pagamento de Sentenças Judiciais até 2010

8 Manutenção da Folha de Pagamento de Sentenças Judiciais até 2010 Messoa Física (SICAP) até 2010

9 Manutenção da Folha de Pagamento do Quadro da FUBRA até 2010

10 Manutenção do Programa Intemo de Estágios até 2010

410 Manter e ampliaro Quadro de Servidores Técnico-Adminis trativos que atenda às necessidades institucionais

1 Dimensionamento do Quadro ideal de Servidores Técnico-Administrat ivos até 2007

2 Articulações junto à Administração Superior e aos Órgãos Competentes para a liberação de vagas de cargos Técnico-Administrativos, de modo a atender às demandas identificadas no Dimensionamento entre 2008 e 2010

3 Reposição de no mínimo $60 \%$ da necessidade de Técnico-Administrativos, de acordo com a demanda identificada até 2010

7 Planejamento e Gestão

$06 \mathrm{D} 1$

1811 Desenvolver Projetos de Pesquisa e Marketing Institucionais

1 Criação e manutenção do Núcleo de Pesquisa e Marketing da SRH até 2010

O6D2

212 Definir e implantar Política de Recursos Humanos em conjunto com a Administração Superior

1 Elaboração e aprovação da Proposta de Política de Recursos Humanos até 2007

2 Definição, no rmatização e implantação da Estrutura da Secretaria de Recursos Humanos até 2007

3 Criação e manutenção de um Núcleo de Vivência Ocupacional para acompanhamento de servidores com problemas de adaptação, integração social e dependências, em parceria com o DAC até 2010

1313 Ampliação do Quadro de CD e FG em 148 funçõ es

1 Ampliação do Quadro de CD e FG em 148 funções até 2010 